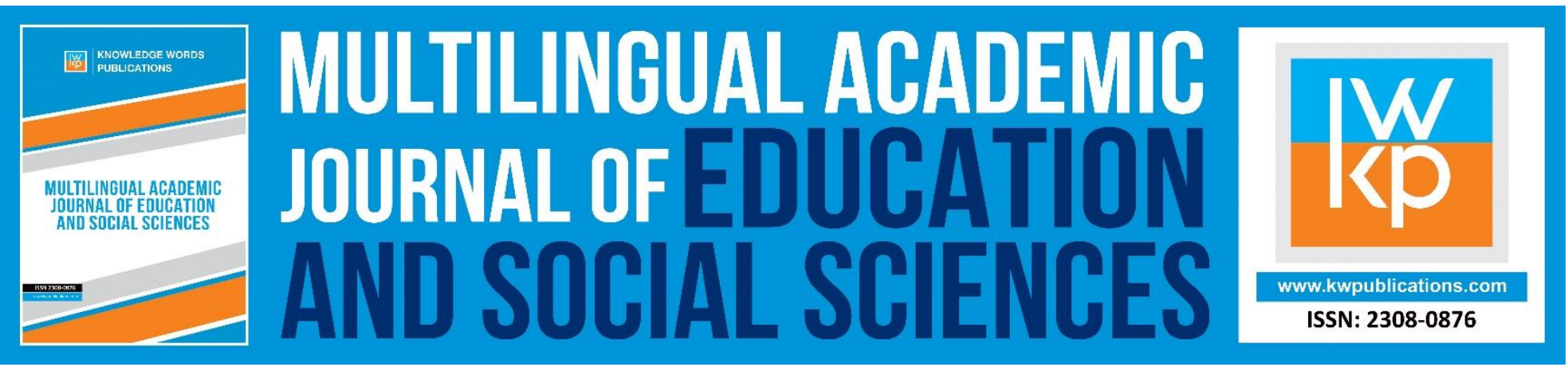

\title{
Language Program «Modern Greek Paideia»: A Record of Educational Needs in the 'Aristotelis' School of Toronto
}

\section{Eleni Griva, Kostas Dinas \& Kostas Flegas}

To Link this Article: http://dx.doi.org/10.46886/MAJESS/v6-i1/4504

DOI: 10.46886/MAJESS/v6-i1/4504

Received: 10 May 2018, Revised: 22 June 2018, Accepted: 30 July 2018

Published Online: 21 August 2018

In-Text Citation: (Griva, Dinas, \& Flegas, 2018)

To Cite this Article: Griva, E., Dinas, K., \& Flegas, K. (2018). Language Program «Modern Greek Paideia»: A Record of Educational Needs in the 'Aristotelis' School of Toronto. Multilingual Academic Journal of Education and Social Sciences, 6(1), 22-34 (in Greek).

\section{Copyright: (C) The Authors 2018}

Published by Knowledge Words Publications (www.kwpublications.com)

This article is published under the Creative Commons Attribution (CC BY 4.0) license. Anyone may reproduce, distribute, translate and create derivative works of this article (for both commercial and non-commercial purposes), subject to full attribution to the original publication and authors. The full terms of this license may be seen at: $\underline{\text { http://creativecommons.org/licences/by/4.0/legalcode }}$

Vol. 6, No. 1, 2018, Pg. 22 - 34

https://kwpublications.com/journals/journaldetail/MAJESS

JOURNAL HOMEPAGE

Full Terms \& Conditions of access and use can be found at https://kwpublications.com/pages/detail/publication-ethics 


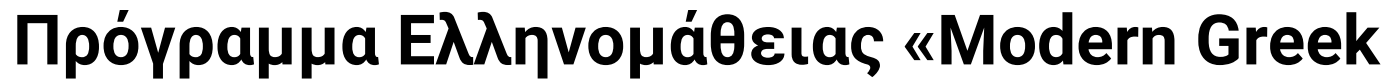

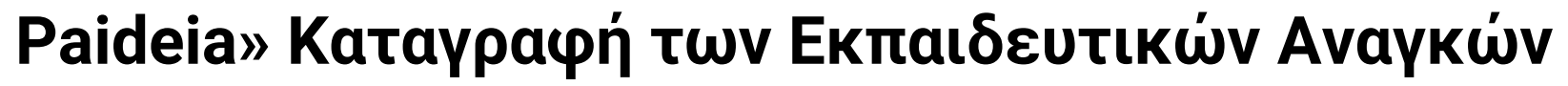

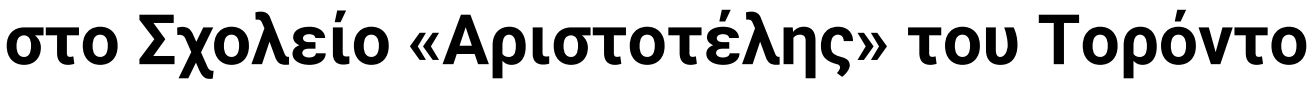

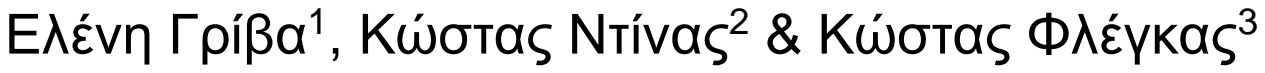

\begin{abstract}
The purpose of this study was to investigate the needs and performance of students attending the "Aristotle" school as well as to record the views of their parents and the teachers' training needs. The "Aristotle" school is the only primary school in Toronto area that is recognized by the Hellenic Republic. Our goal was to collect data would help us better understand the thoughts and needs of the school community, in an attempt to achieve a common goal of providing the highest quality of Greek Language Paideia. Taking into consideration the gathered needs, and the guidelines for language acquisition described in the Common European Framework of Reference for Languages (CEF, 2001), the Modern Greek Paideia Program was developed by professors and researchers of the University of Western Macedonia in collaboration with the Greek Community of Toronto. It is tailored to meet the needs and interests of students who learn Greek as a second/foreign language in Canada, and it is a student centered, flexible language program that promotes intercultural communication, and aims at developing multi-literacies skills, cognitive and metacognitive language strategies, enhancing students' creativity and critical thinking skills, and promoting bilingual awareness (by helping students make connections between English and Greek).
\end{abstract}

Keywords: Language Program, Educational Needs, Teacher Training.

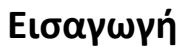

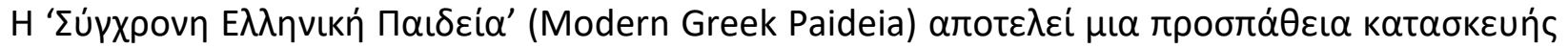

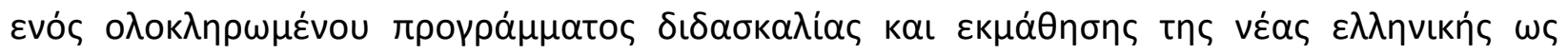

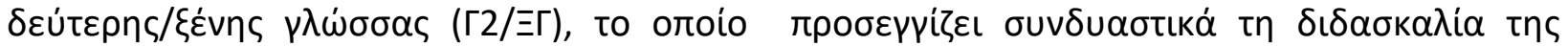

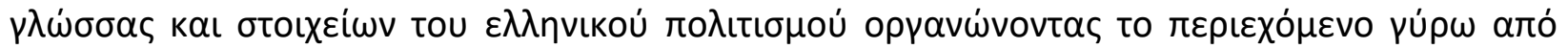

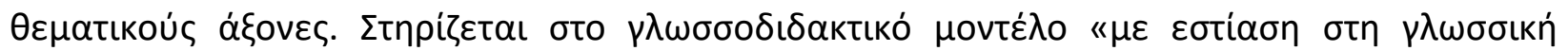

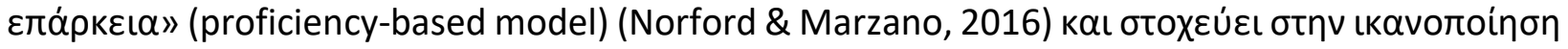

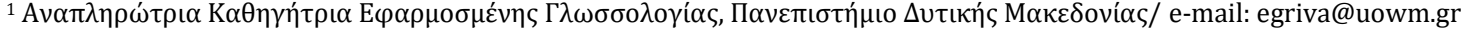

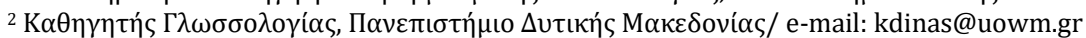

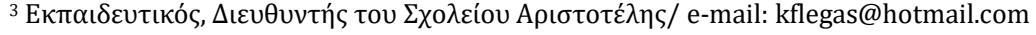




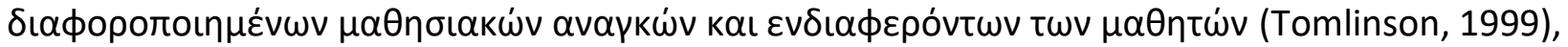

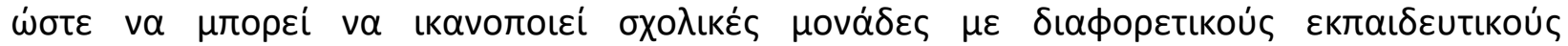

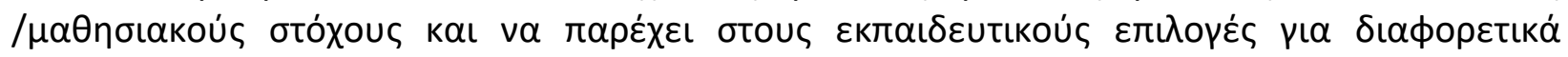

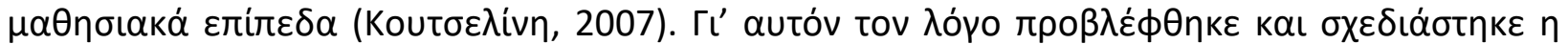

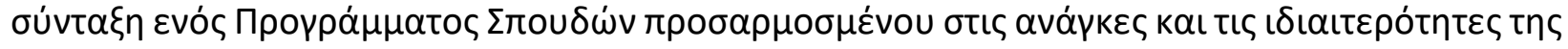

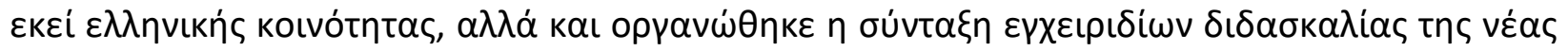

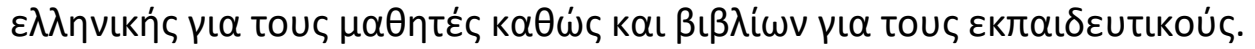

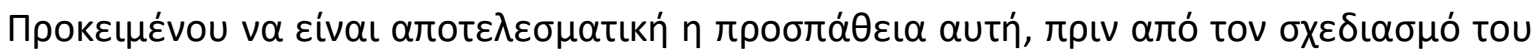

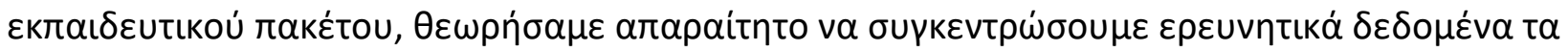

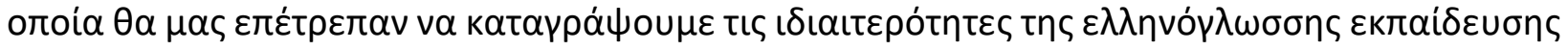

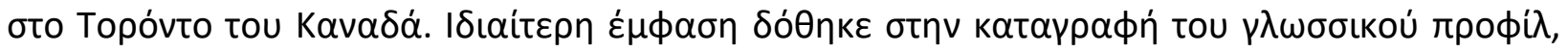

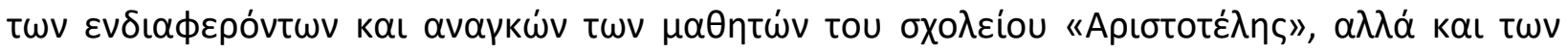

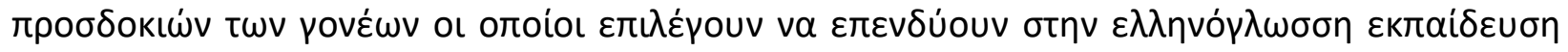
$\tau \omega \nu \pi \alpha \iota \delta \iota \omega \dot{v}$ tous.

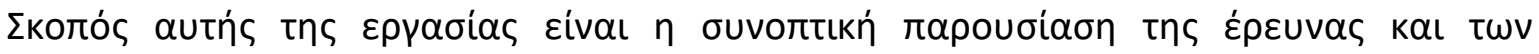

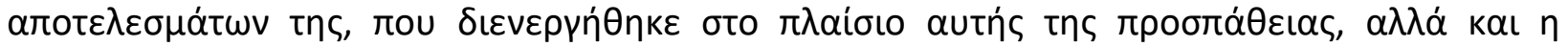

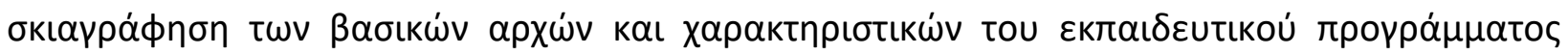
«Modern Greek Paideia».

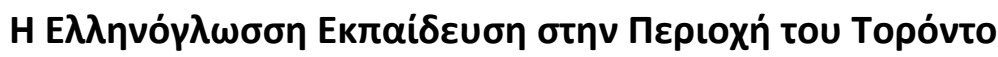

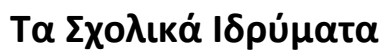

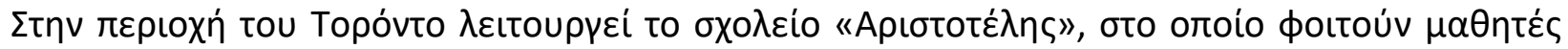

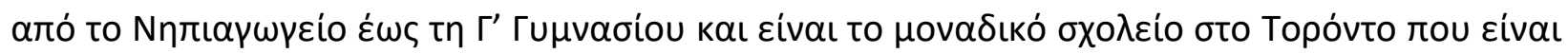

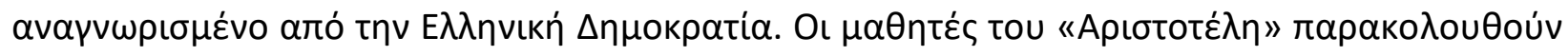

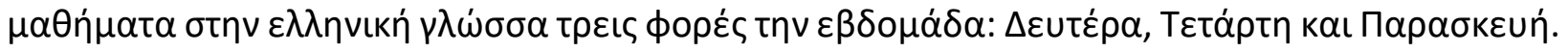

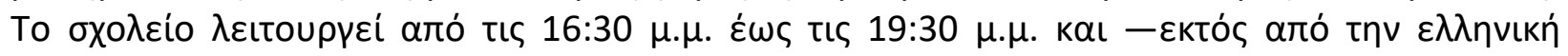

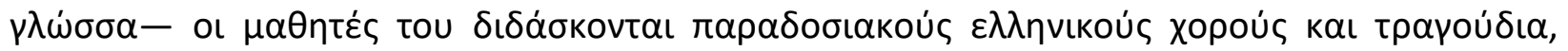

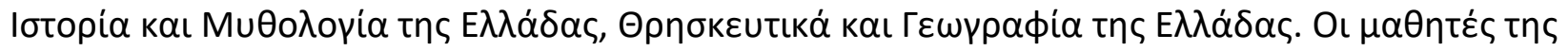

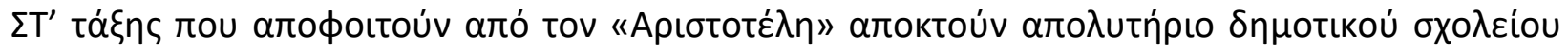

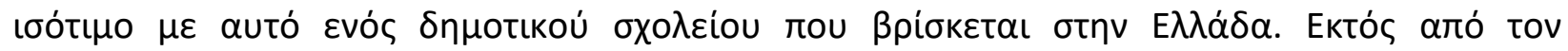

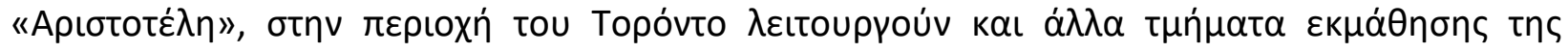

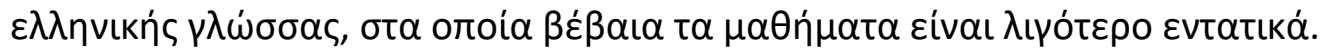

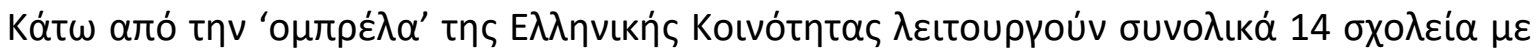

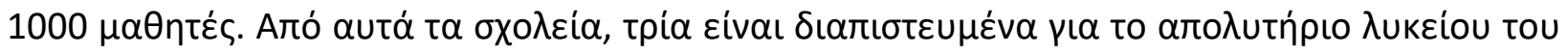

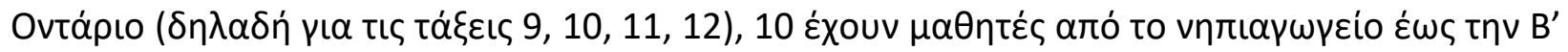

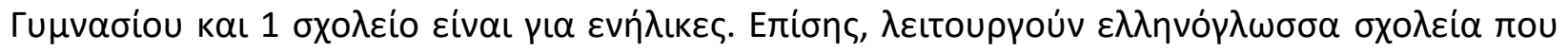

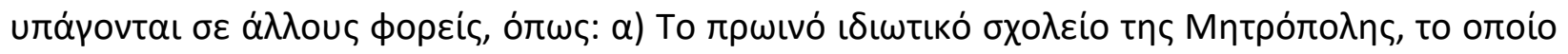

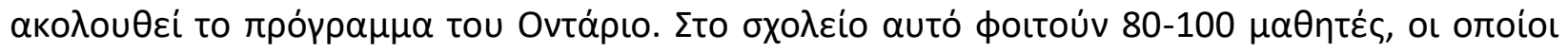

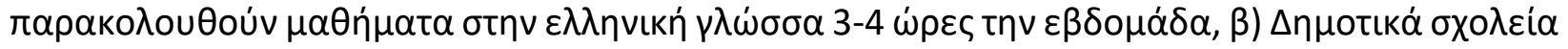

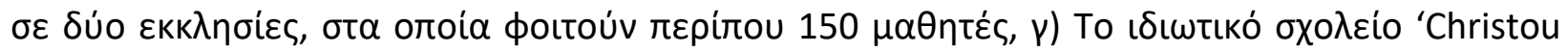

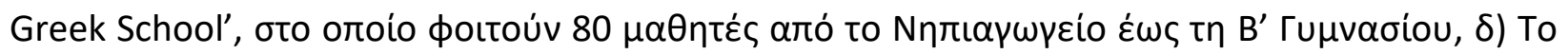

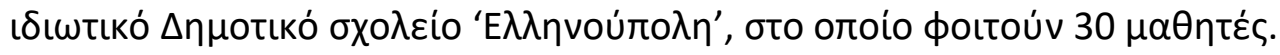


MULTILINGUAL ACADEMIC JOURNAL OF EDUCATION AND SOCIAL SCIENCES

Vol. 6 No. 1, 2018, E-ISSN: 2308-0876 ๔ 2018 KWP

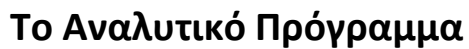

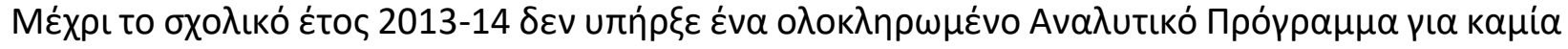

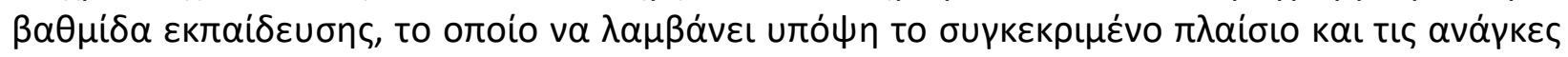

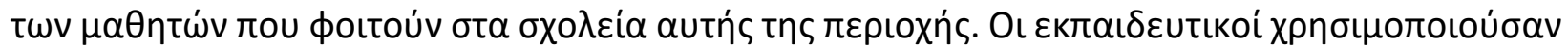

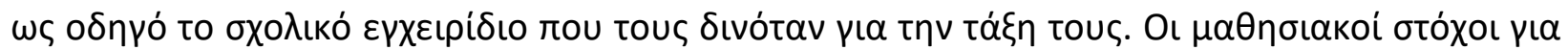

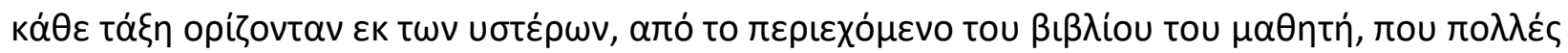

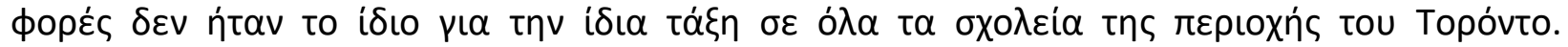

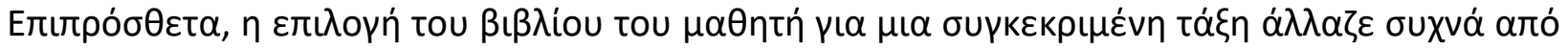

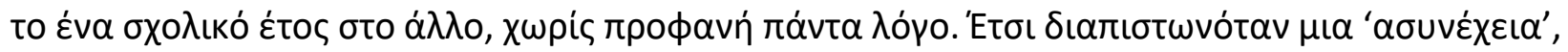

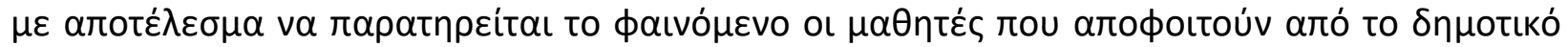

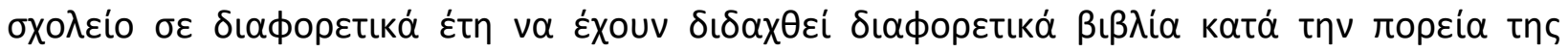
фoítnońs tous.

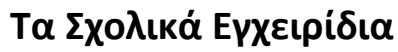

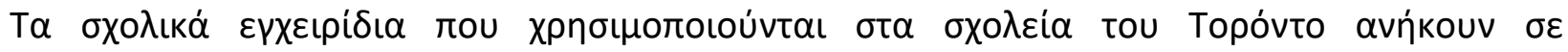

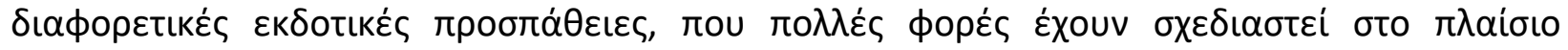

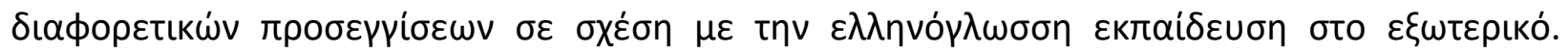

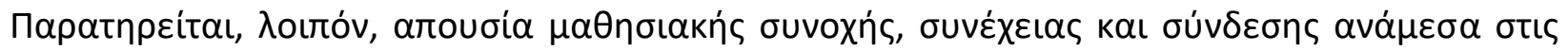

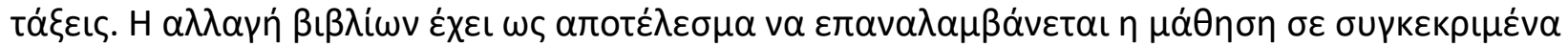

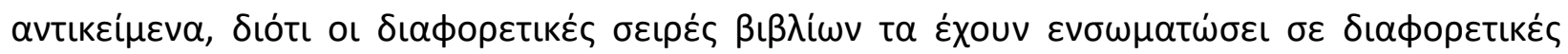

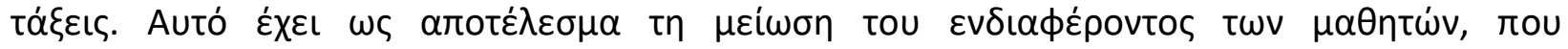

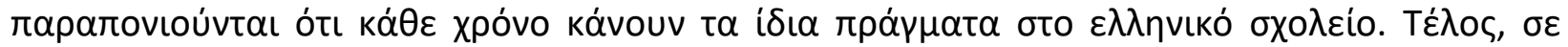

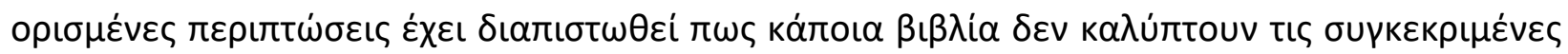

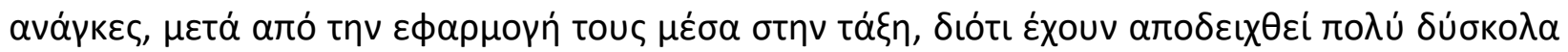

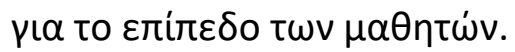

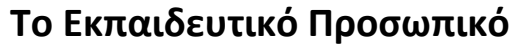

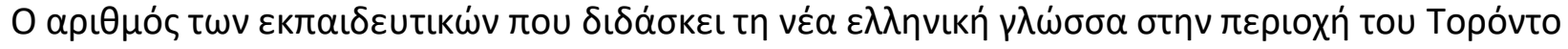

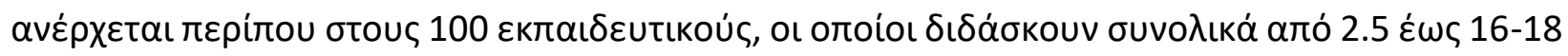

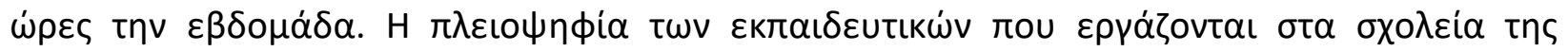

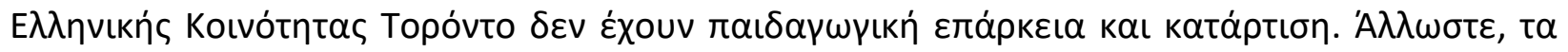

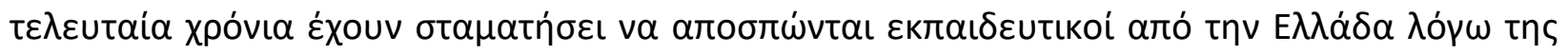

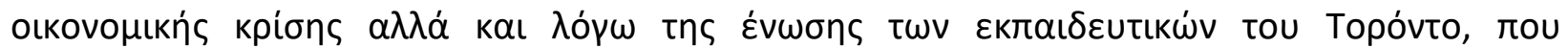

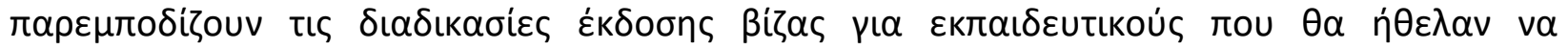

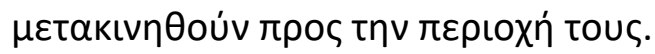

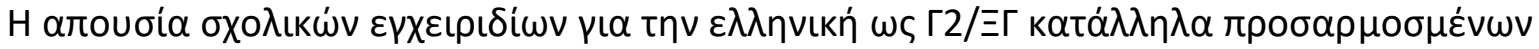

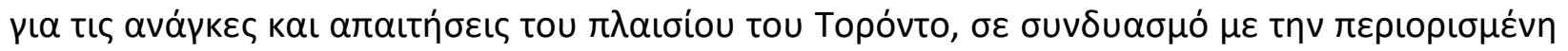

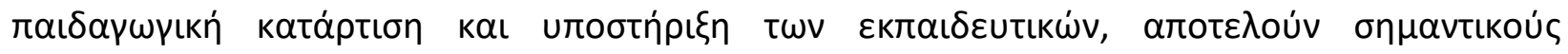

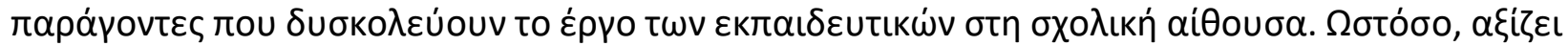

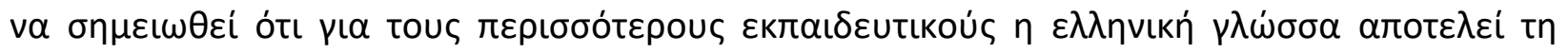

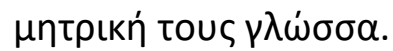

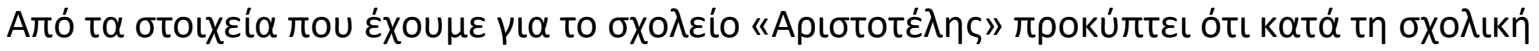

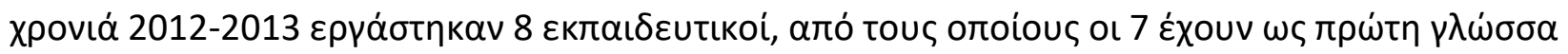

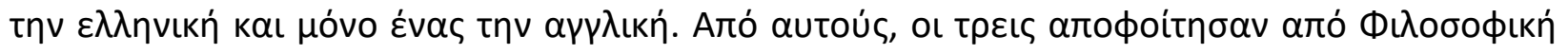




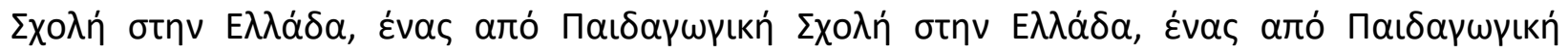

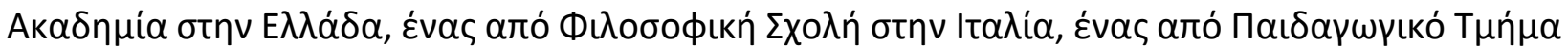

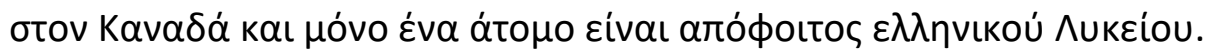

\section{H'Epquva}

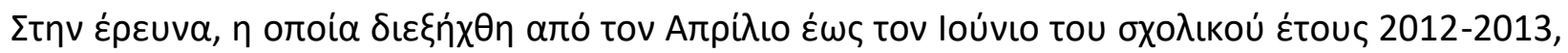

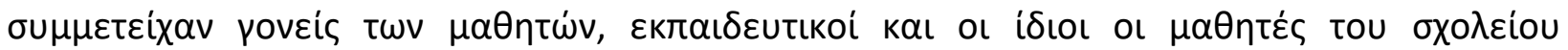

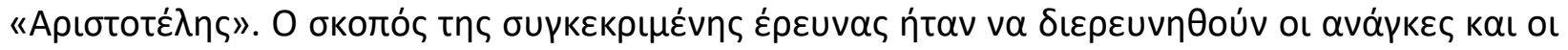

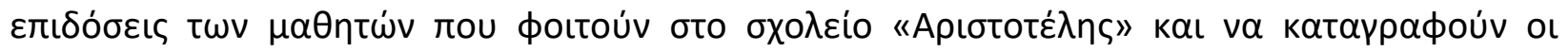

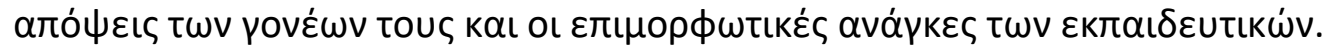

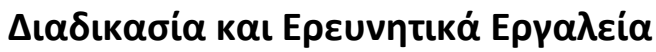

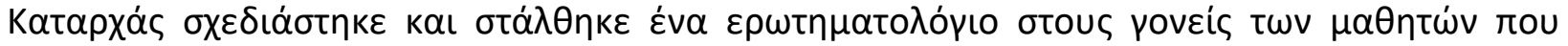

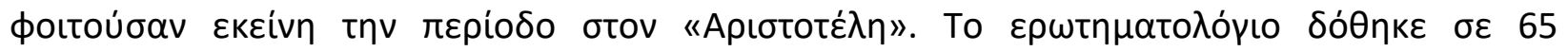

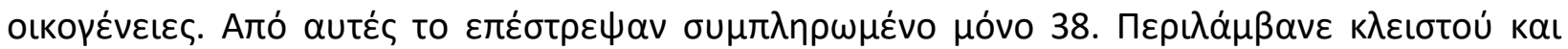

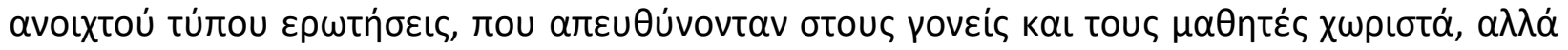

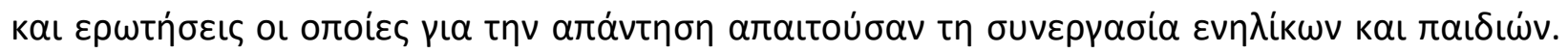

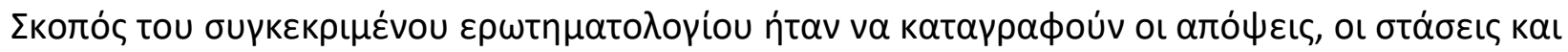

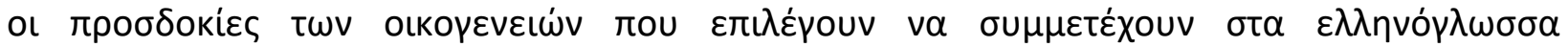

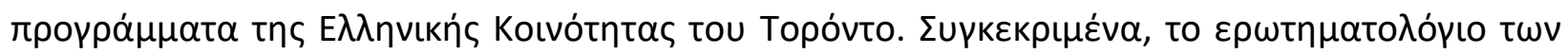

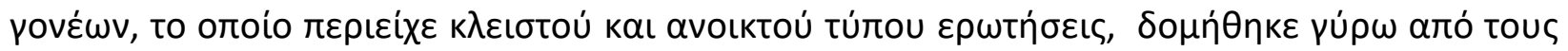

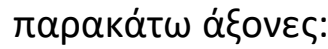

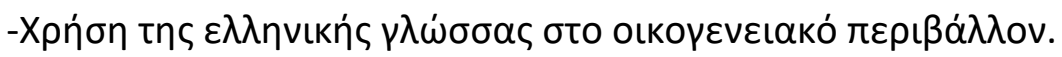

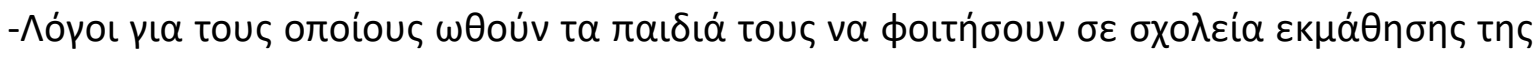
$\varepsilon \lambda \lambda \eta v i k n ́ s ~ \gamma \lambda \omega \dot{\sigma \sigma \alpha \alpha}$.

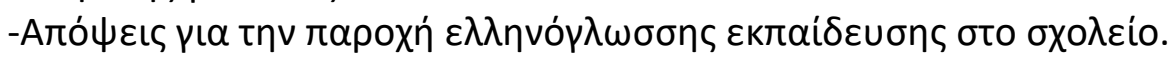

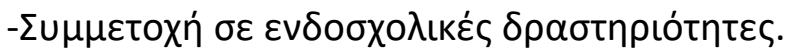

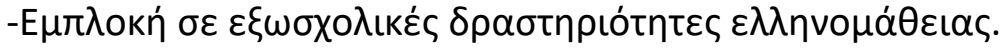

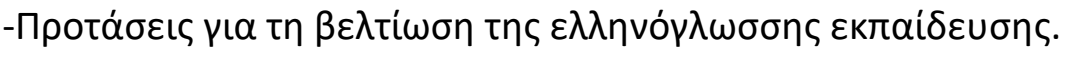

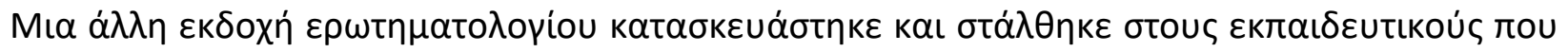

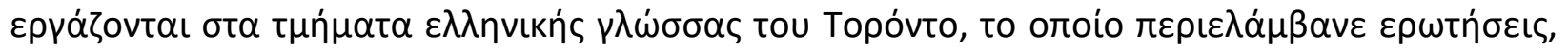

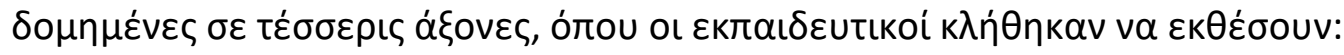

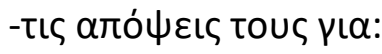

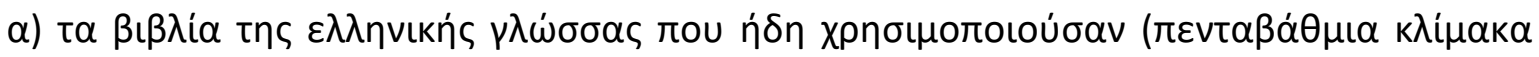

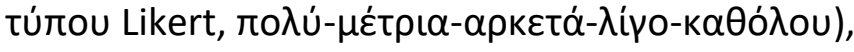

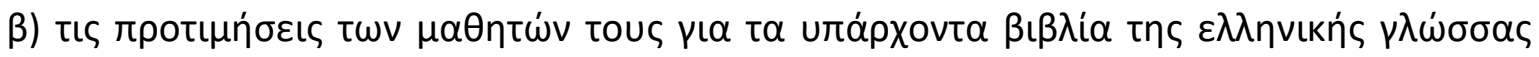

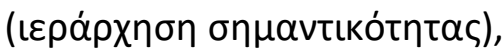

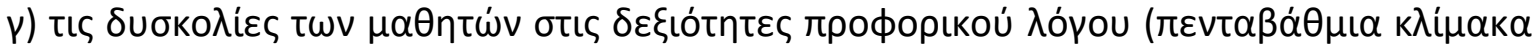

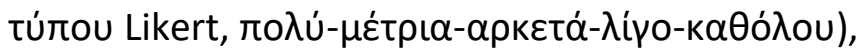

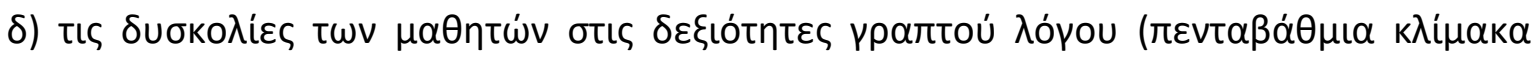

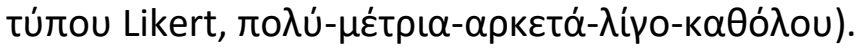

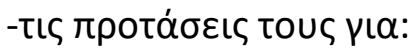




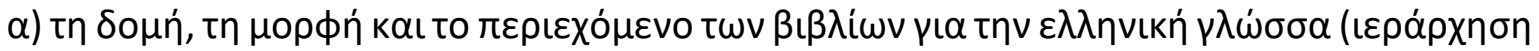

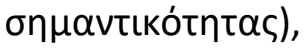

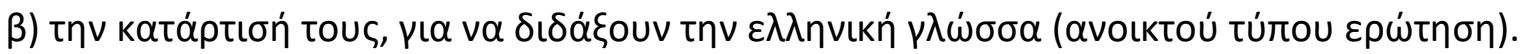

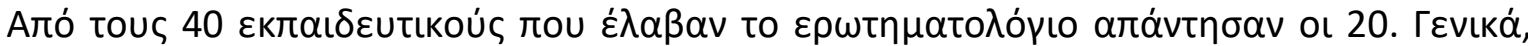

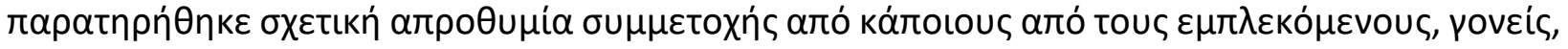

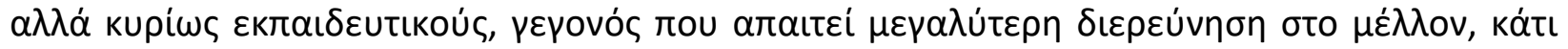

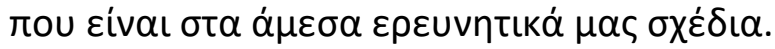

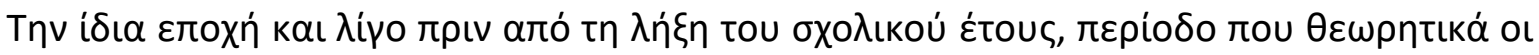

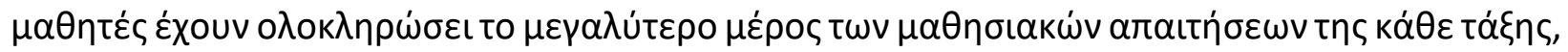

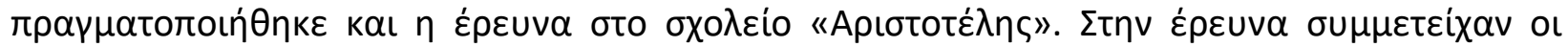

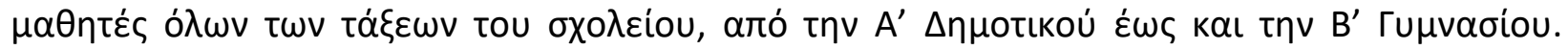

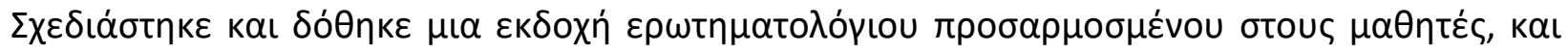

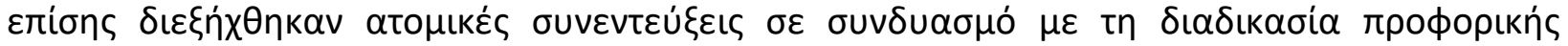

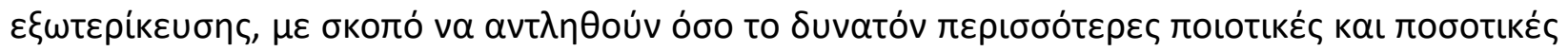
$\pi \lambda \eta \rho о ф о \rho і \varepsilon \varsigma$.

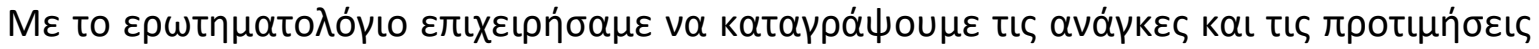

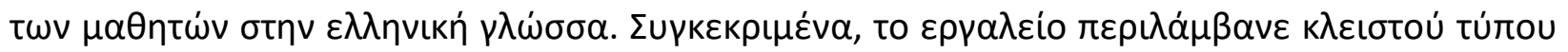

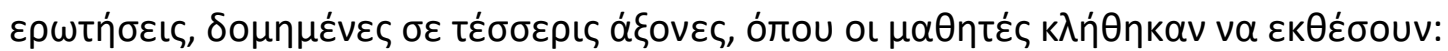

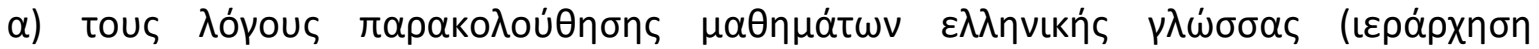

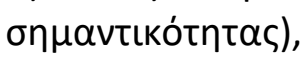

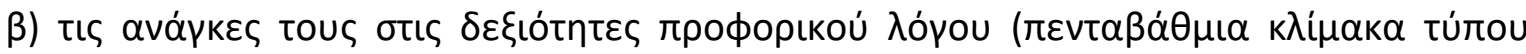

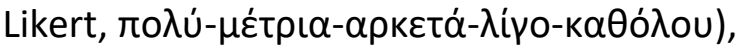

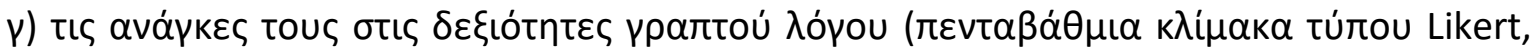

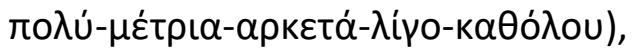

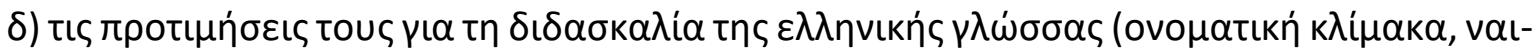

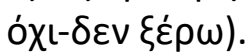

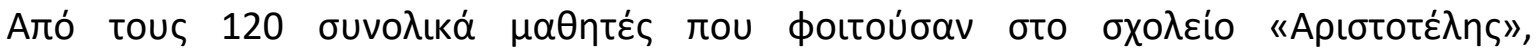

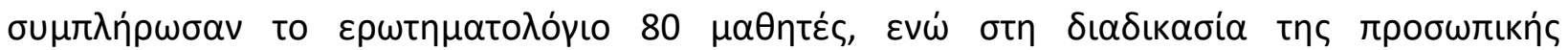

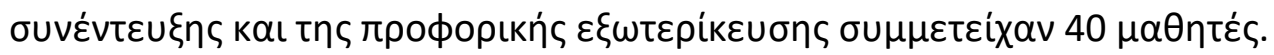

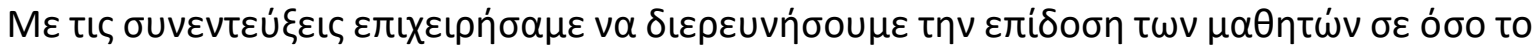

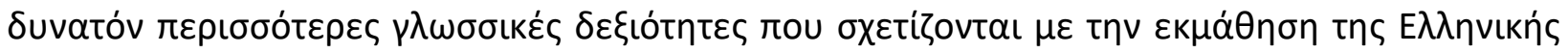

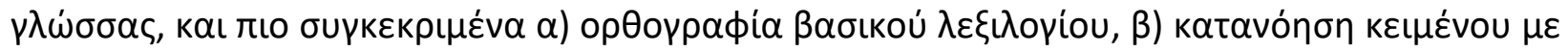

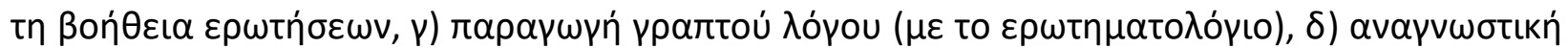

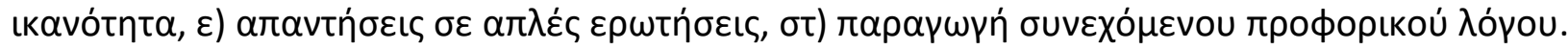

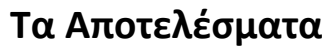

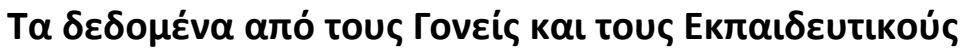

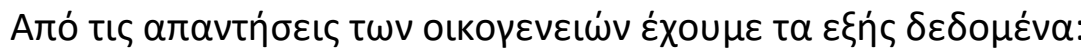

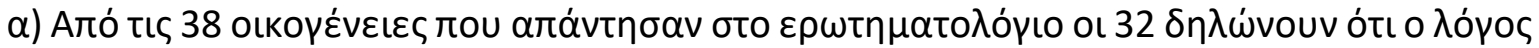

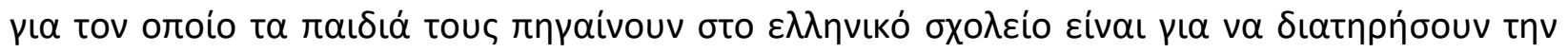

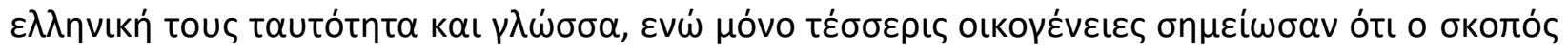

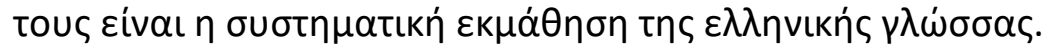

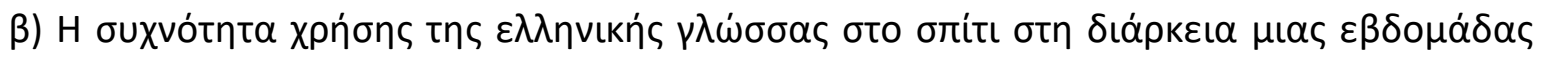

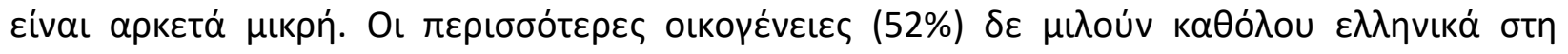




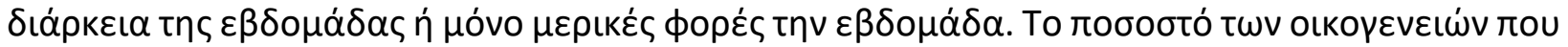

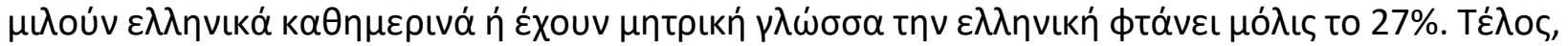

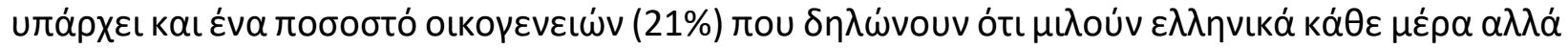

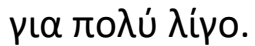

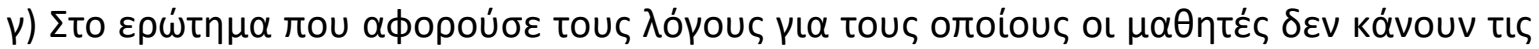

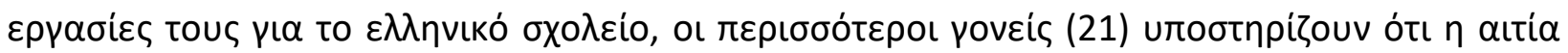

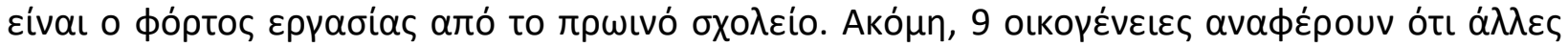

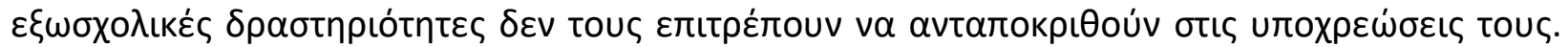

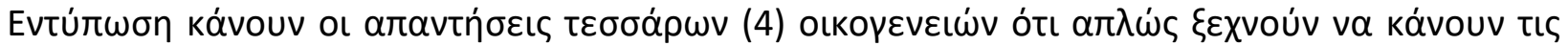

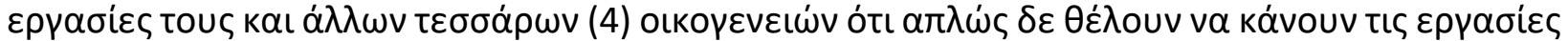

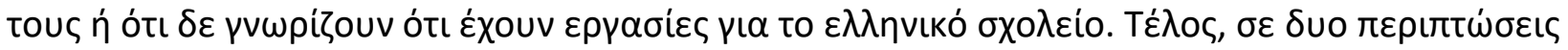

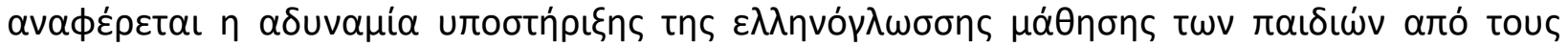

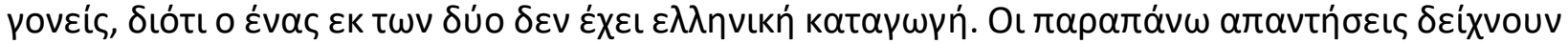

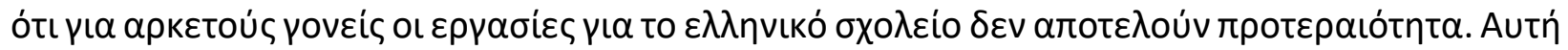

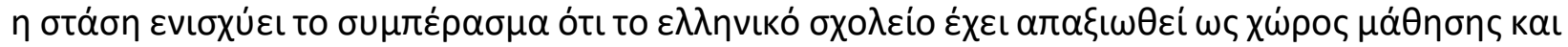

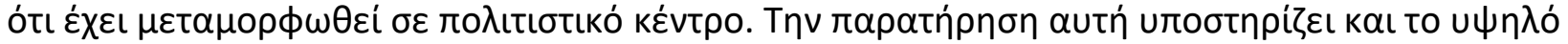

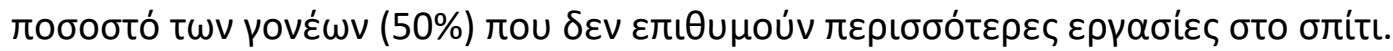

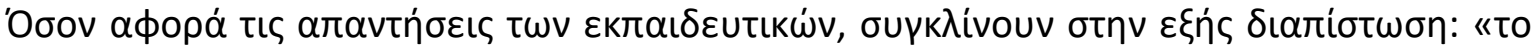

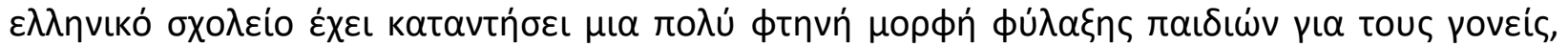

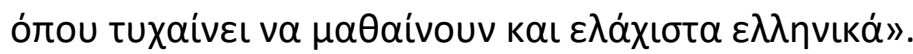

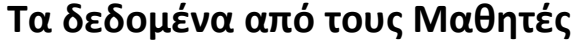

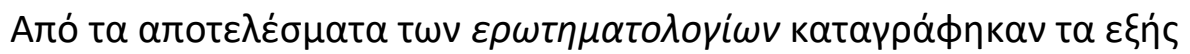

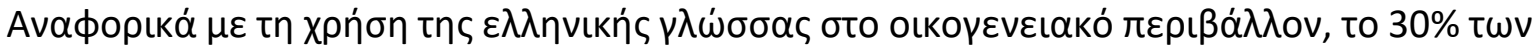

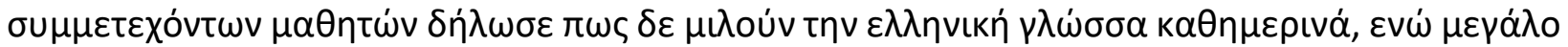

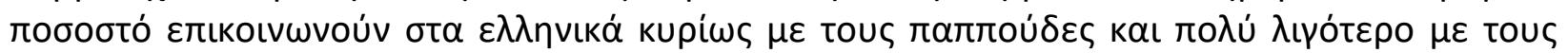
poveís tous.

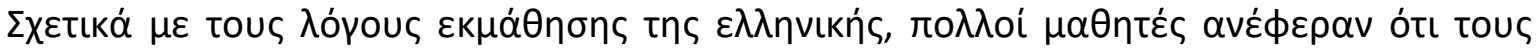

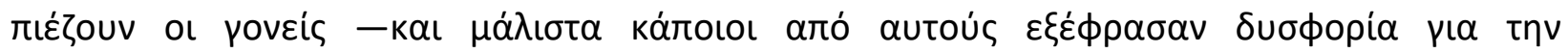

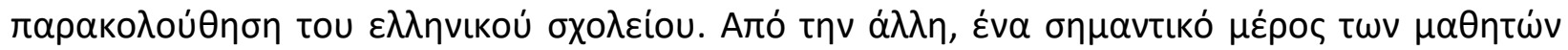

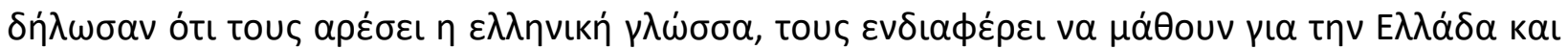

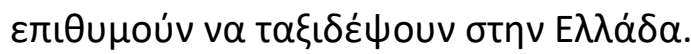

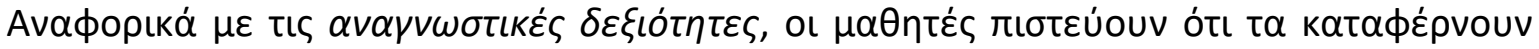

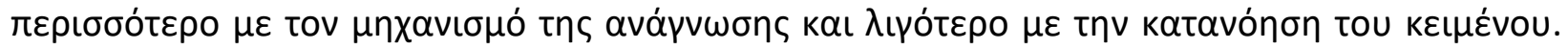

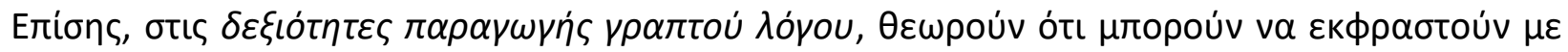

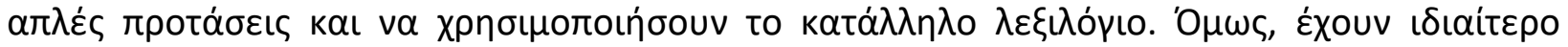

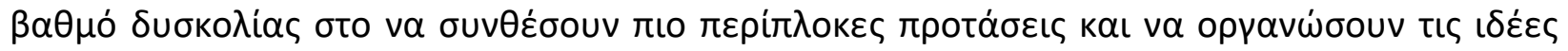

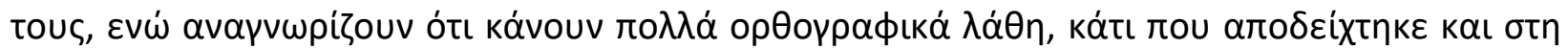

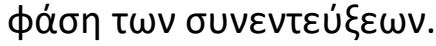

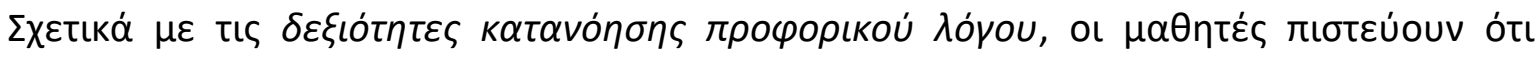

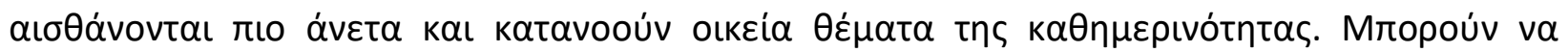

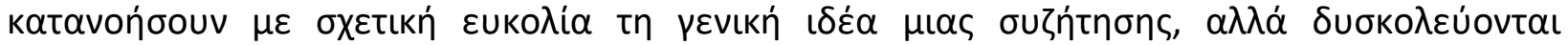

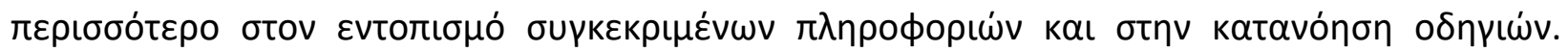

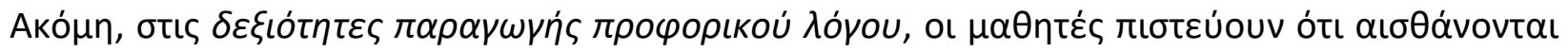




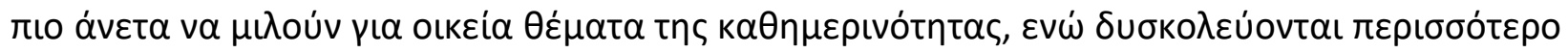

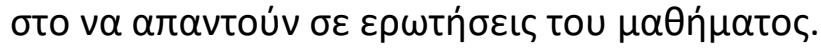

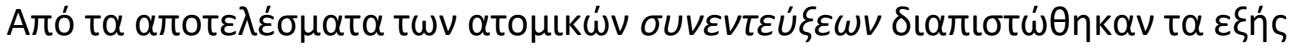

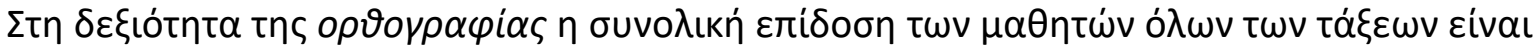

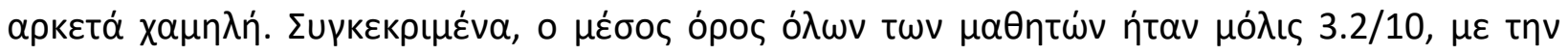

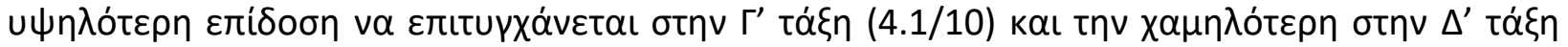

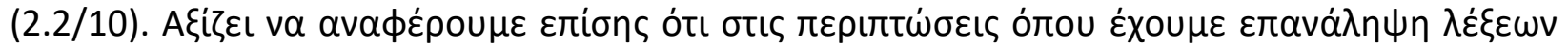

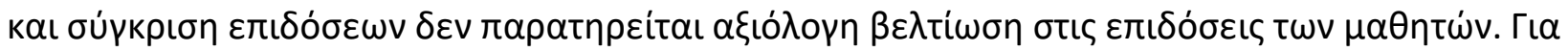

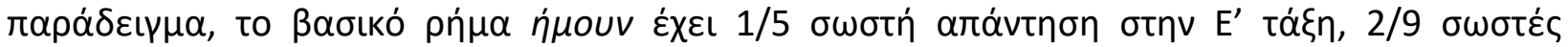

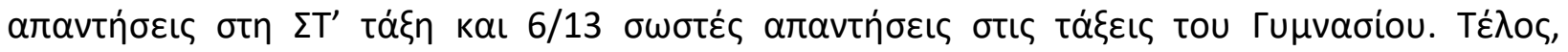

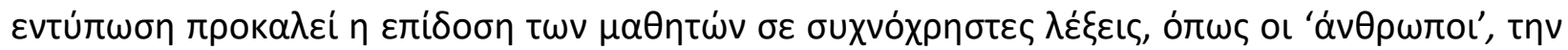

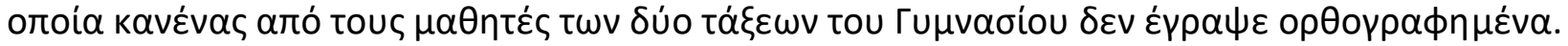

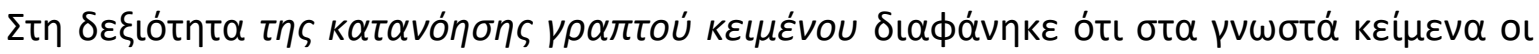

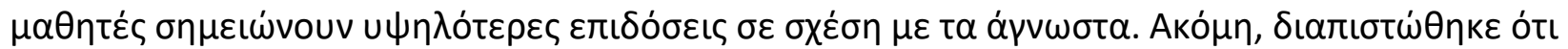

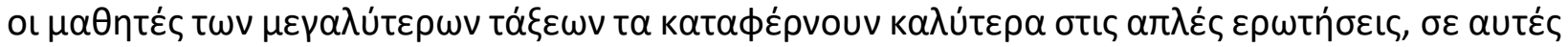

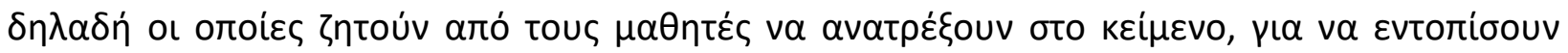

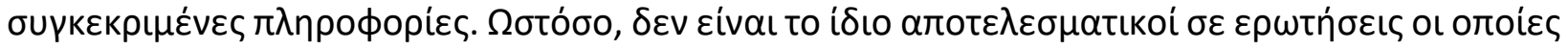

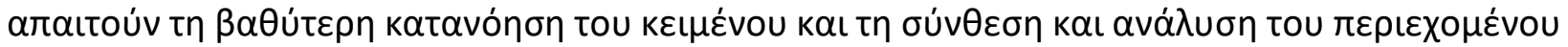

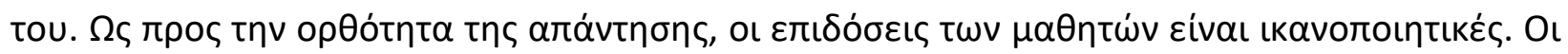

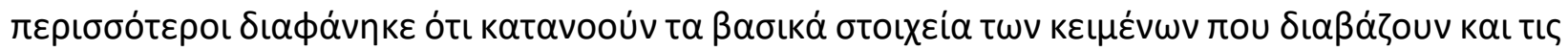

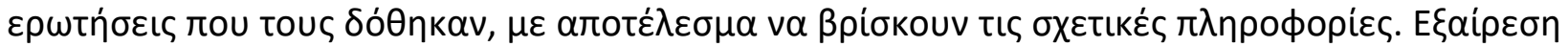

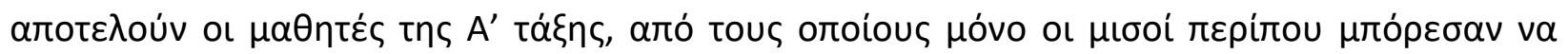

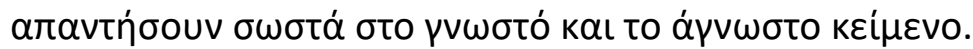

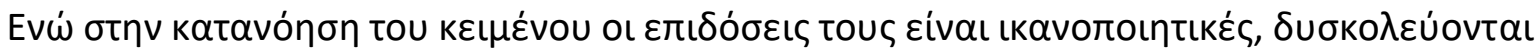

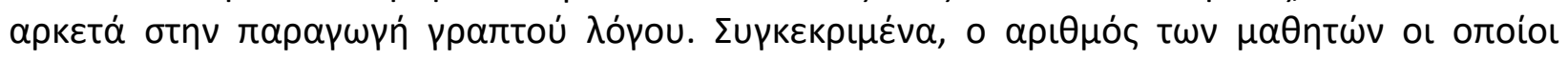

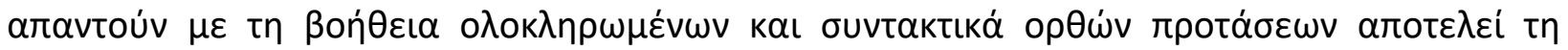

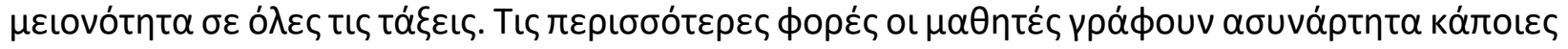

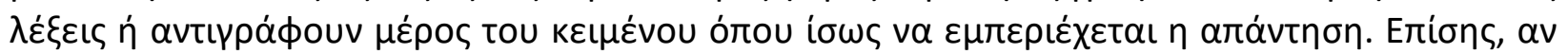

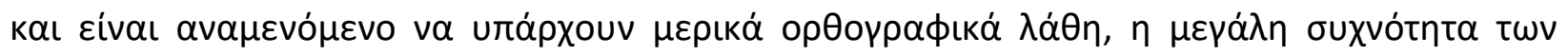

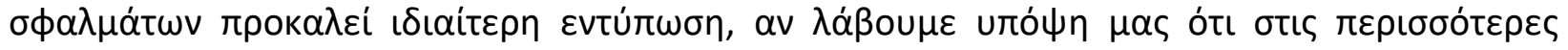
$\pi \varepsilon \rho$ เाт்́

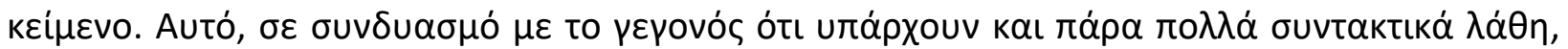

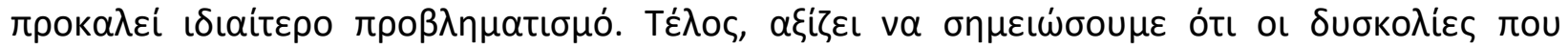

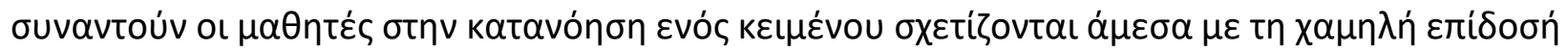

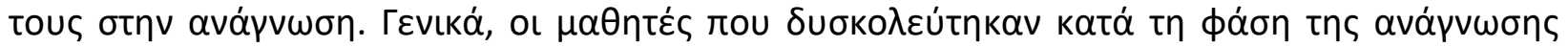

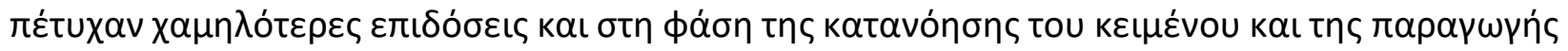

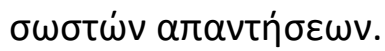

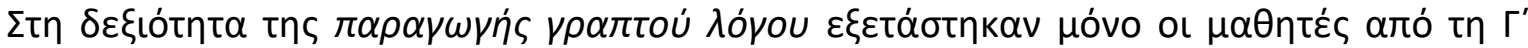

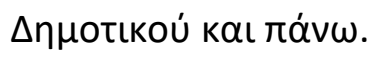

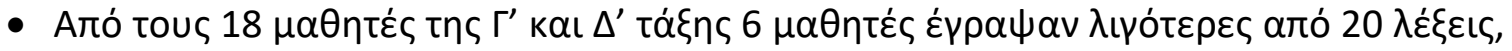

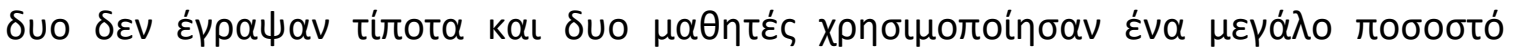

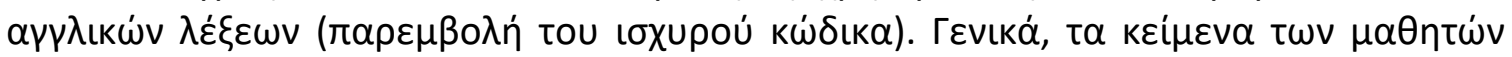

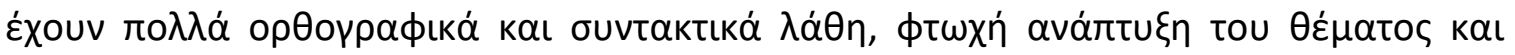




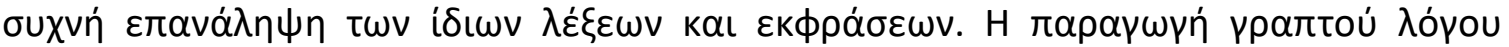

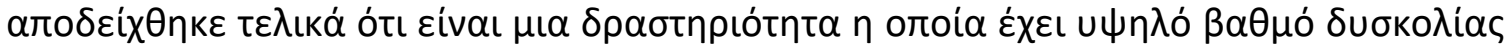

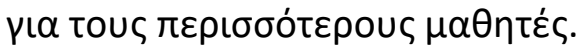

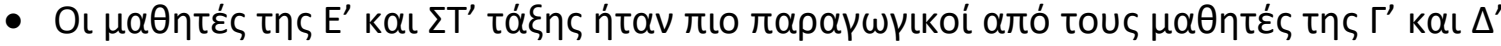

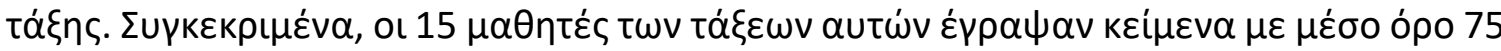

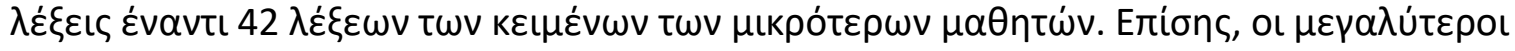

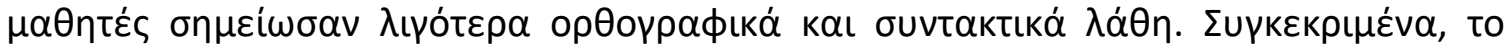

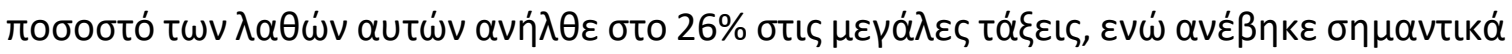

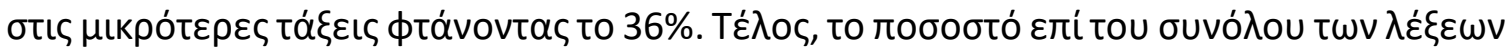

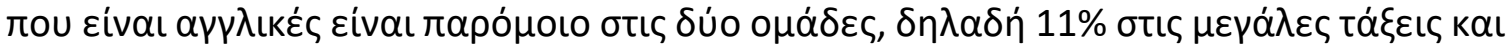

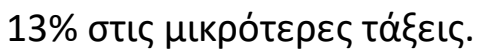

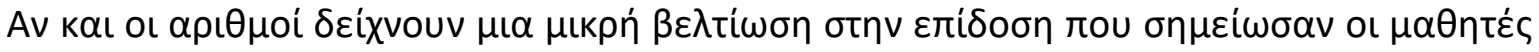

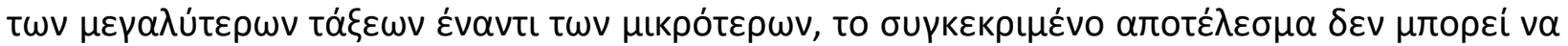

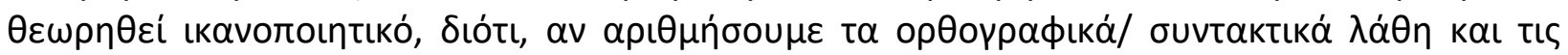

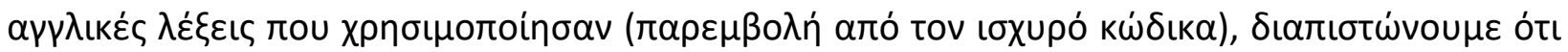

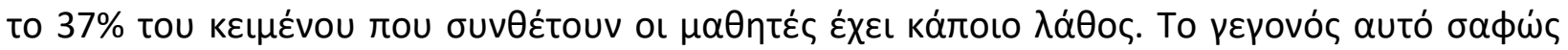

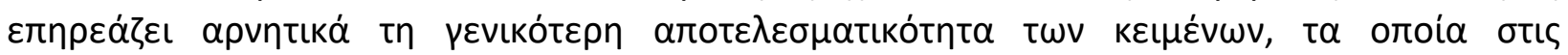

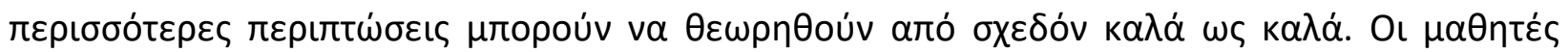

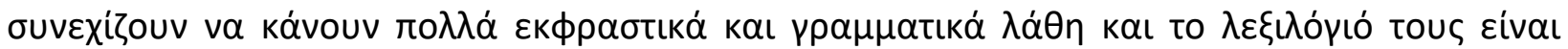

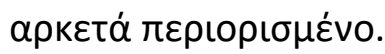

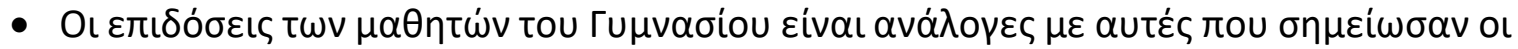

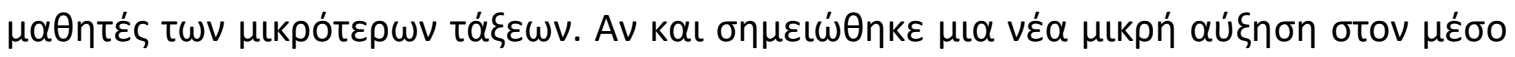

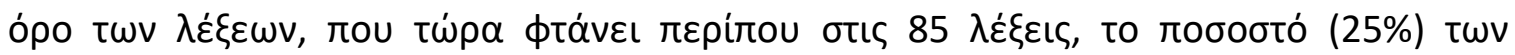

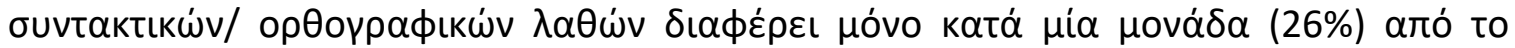

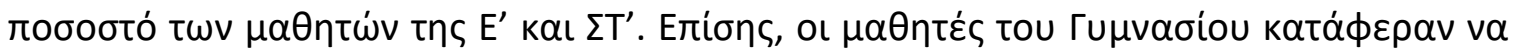

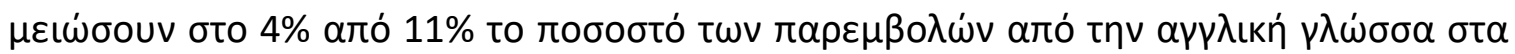

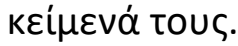

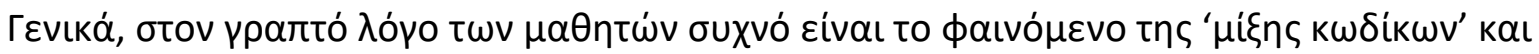

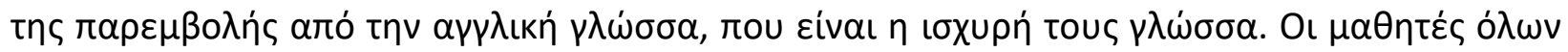

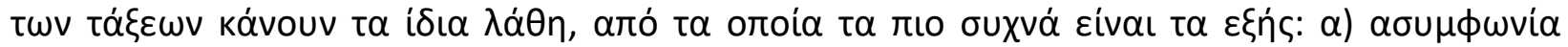

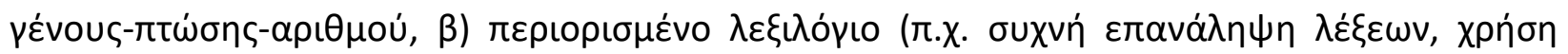

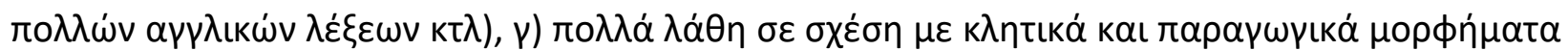

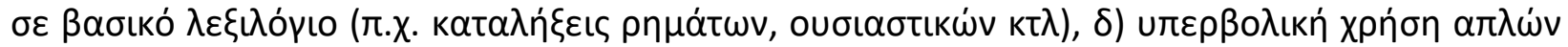

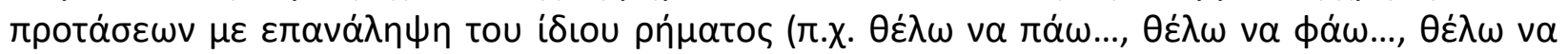

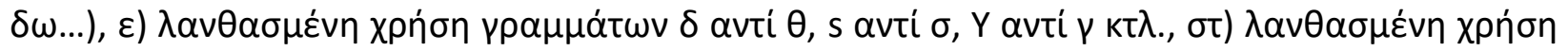

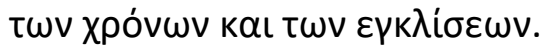

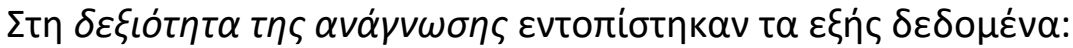

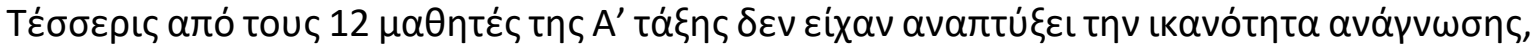

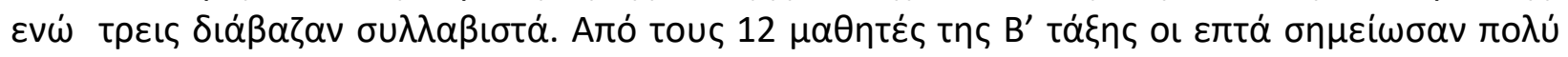

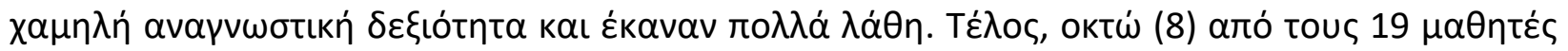

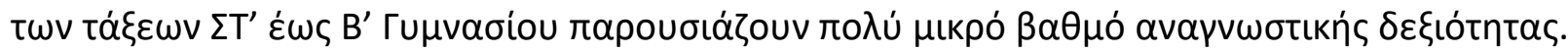




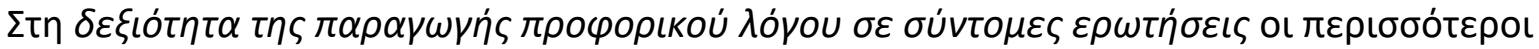

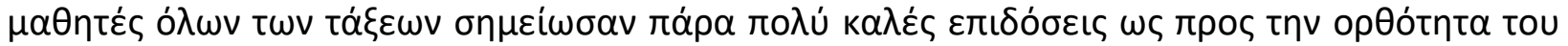

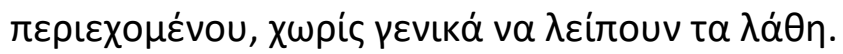

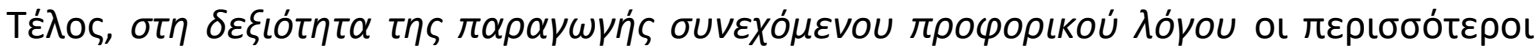

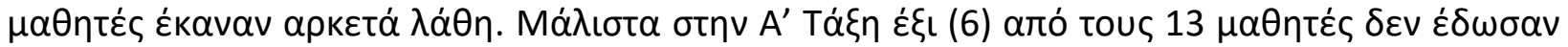

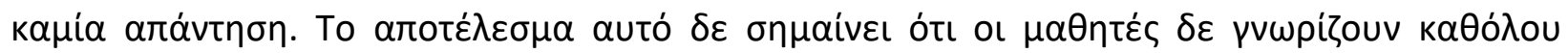

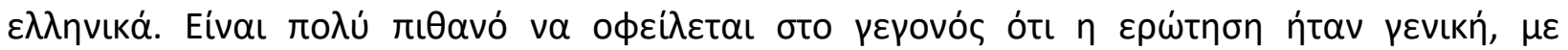

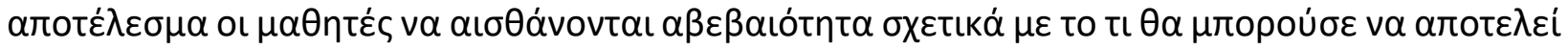

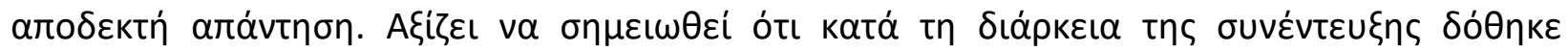

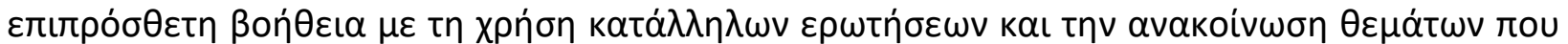

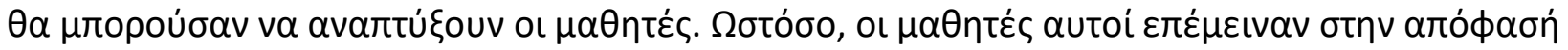

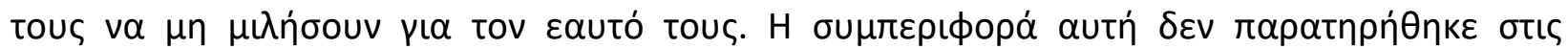

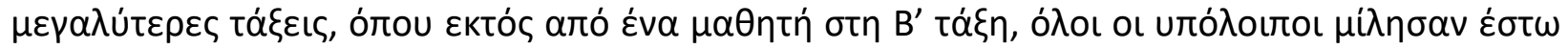

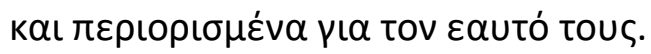

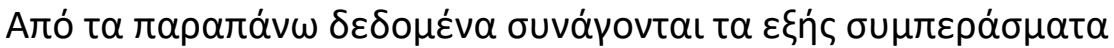

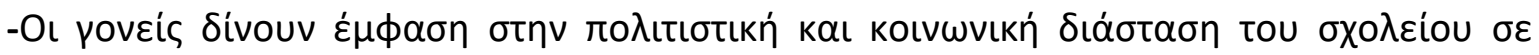

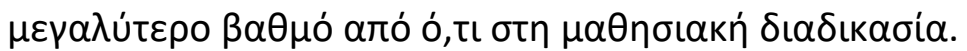

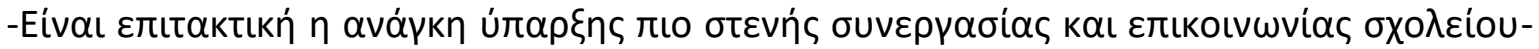

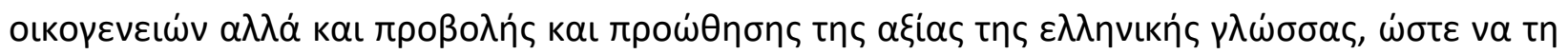

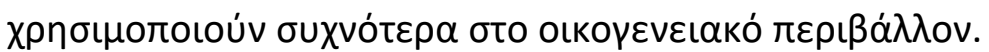

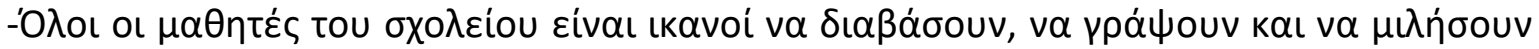

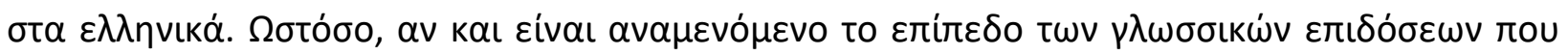

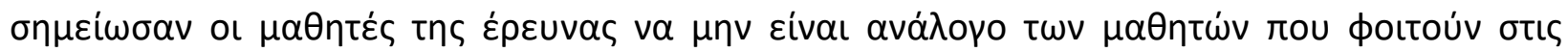

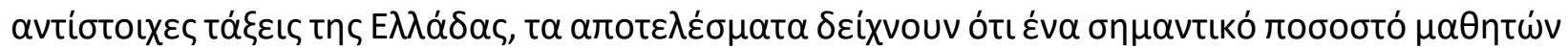

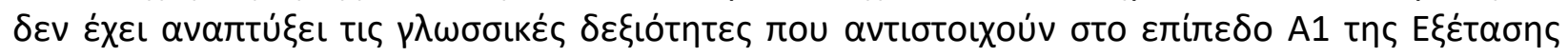

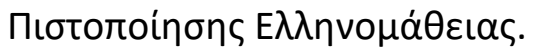

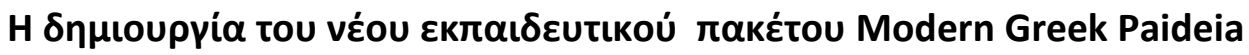

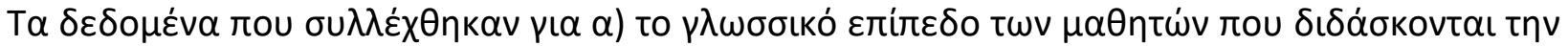

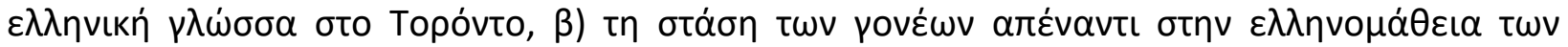

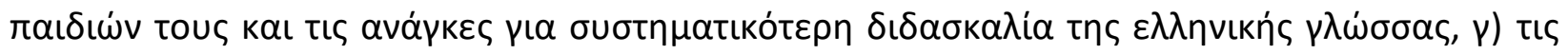

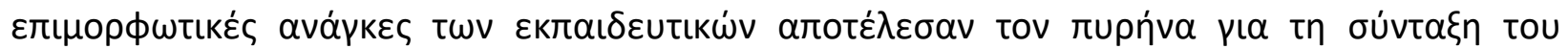

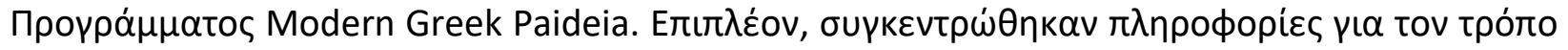

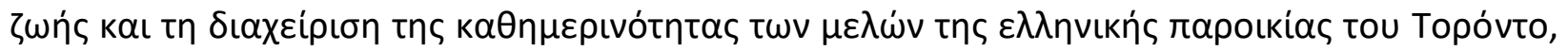

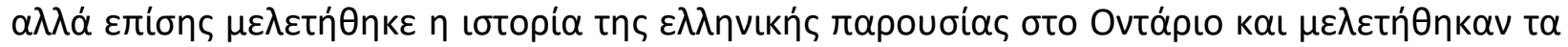

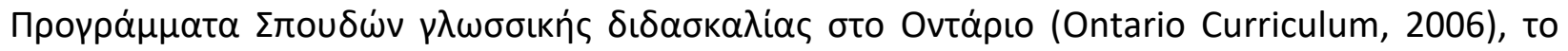

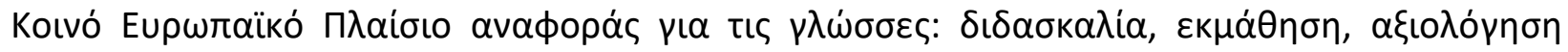

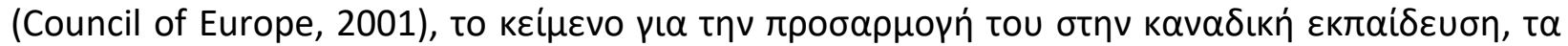

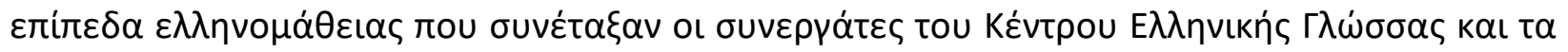

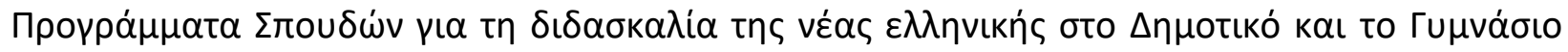

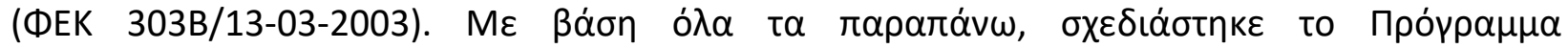

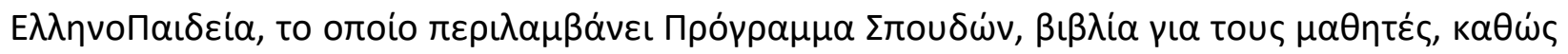

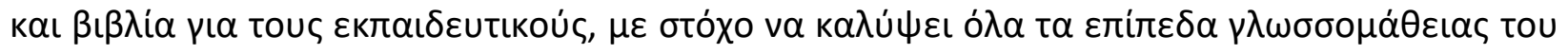


MULTILINGUAL ACADEMIC JOURNAL OF EDUCATION AND SOCIAL SCIENCES

Vol. 6 No. 1, 2018, E-ISSN: 2308-0876 ๔ 2018 KWP

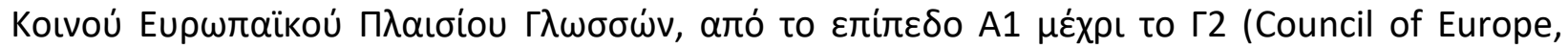
2001).

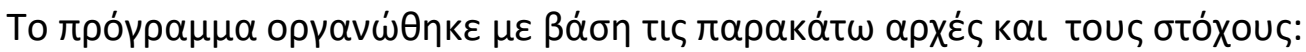

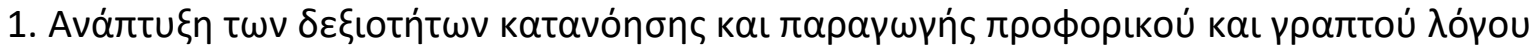

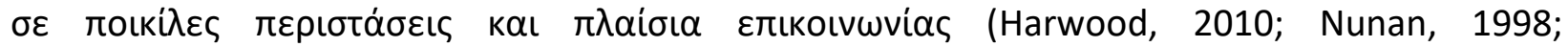

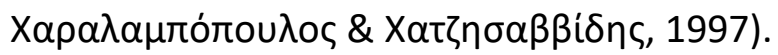

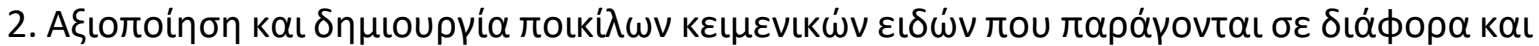

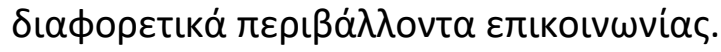

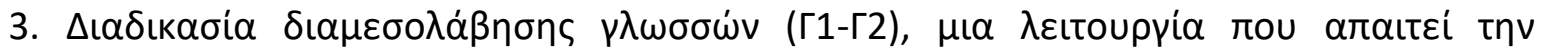

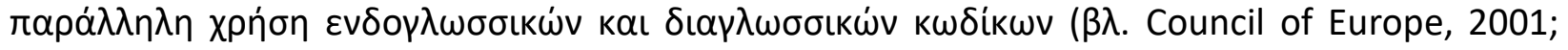
Rudvin \& Spinzi, 2014).

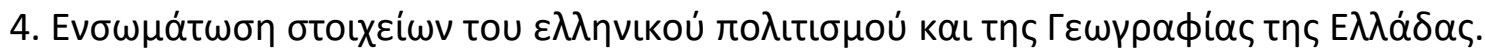

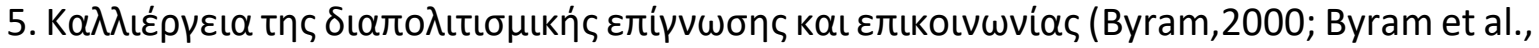
2002).

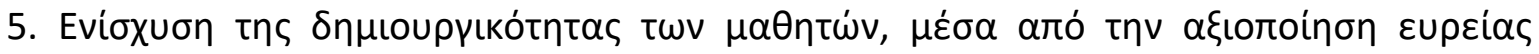

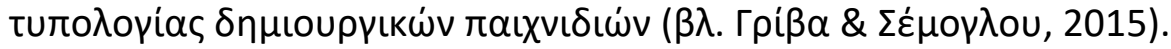

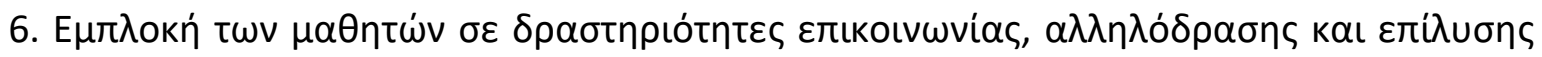
$\pi \rho о \beta \lambda \dot{\mu \alpha \alpha \tau \varsigma ~(~} \beta \lambda$. Bourke, 1992; Sheen, 1992).

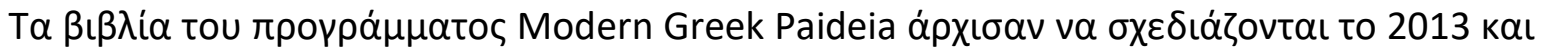

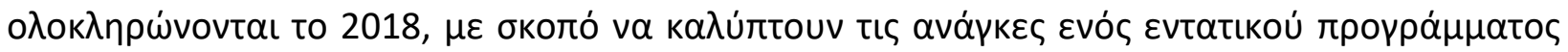

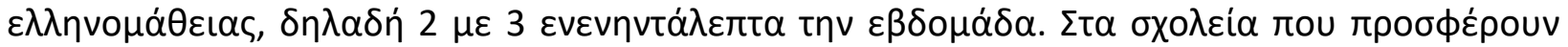

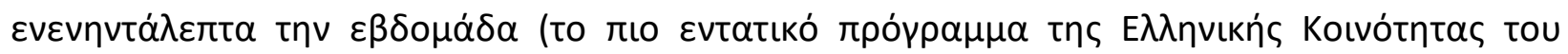

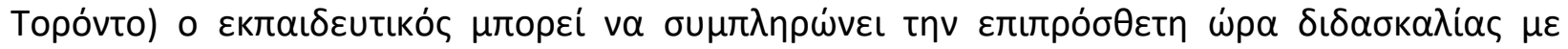

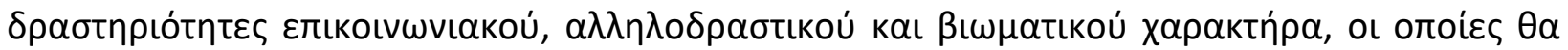

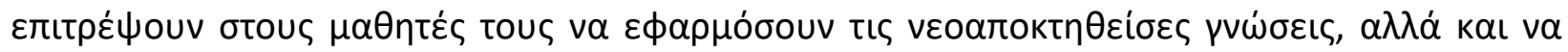

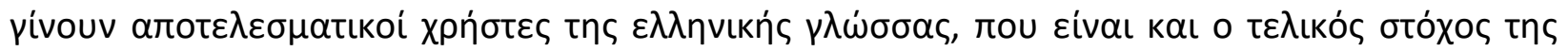

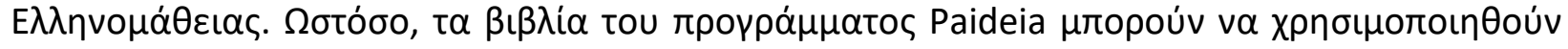

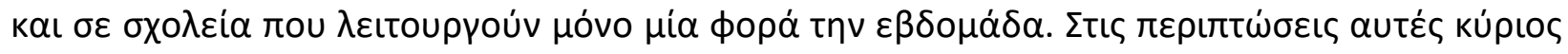

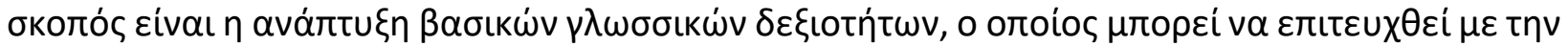

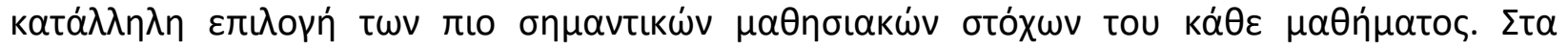

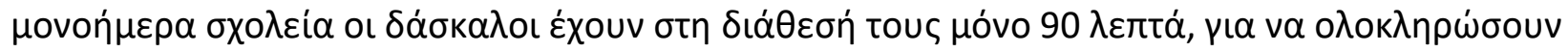

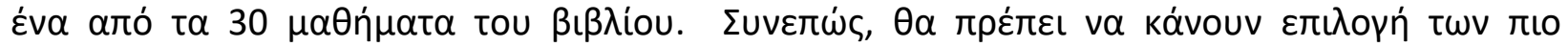

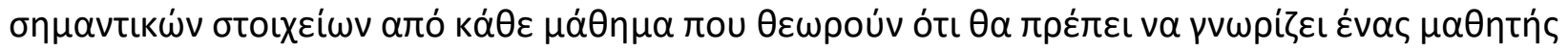
ท่ $\mu \alpha \theta \dot{\tau} \tau \rho \alpha$.

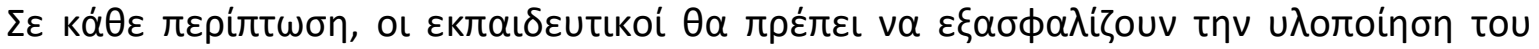

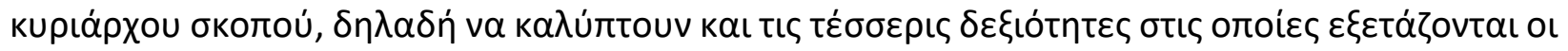

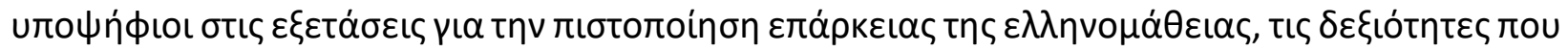

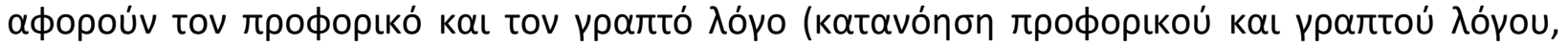

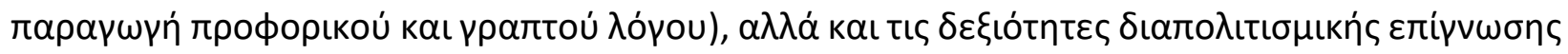

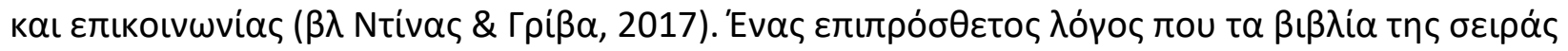

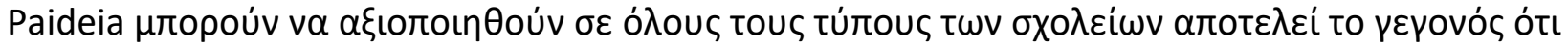

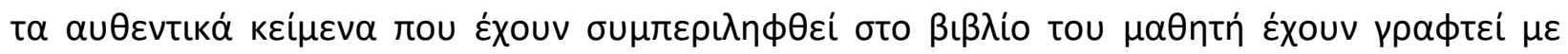

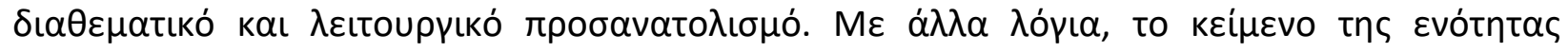


MULTILINGUAL ACADEMIC JOURNAL OF EDUCATION AND SOCIAL SCIENCES

Vol. 6 No. 1, 2018, E-ISSN: 2308-0876 @ 2018 KWP

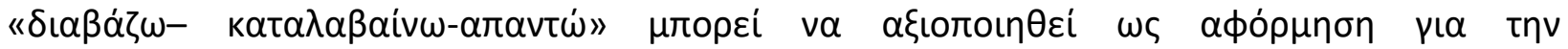

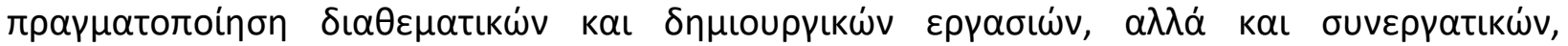

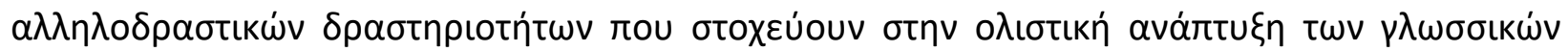

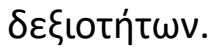

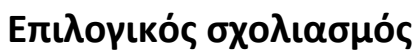

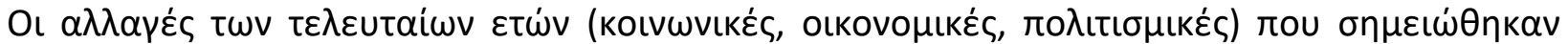

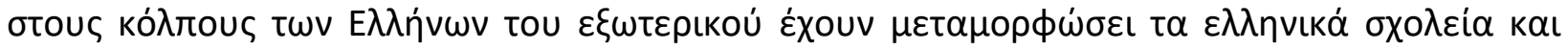

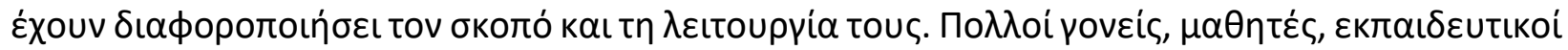

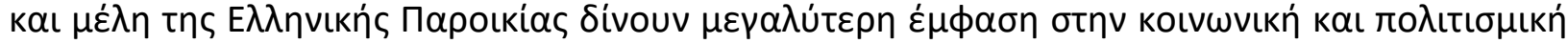

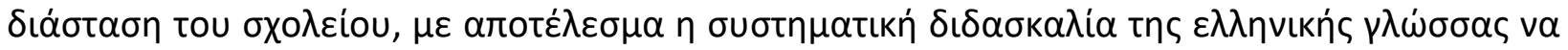

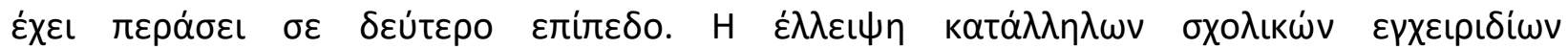

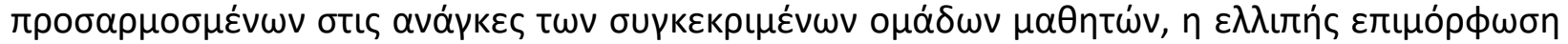

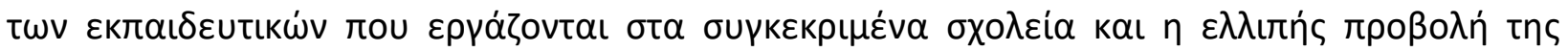

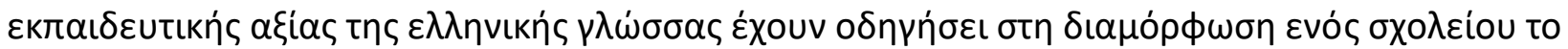

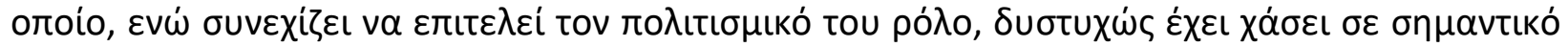

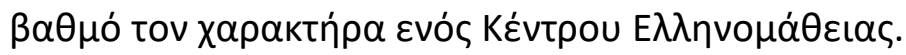

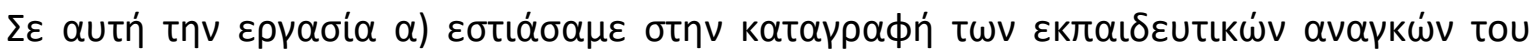

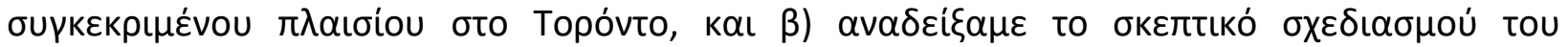

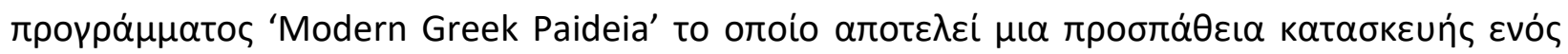

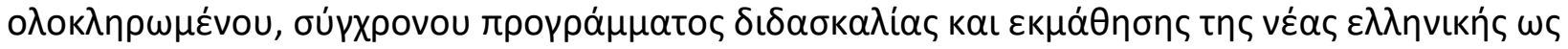

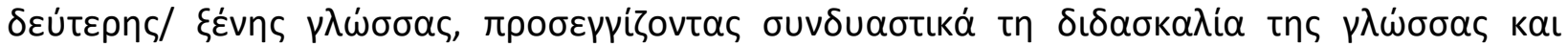

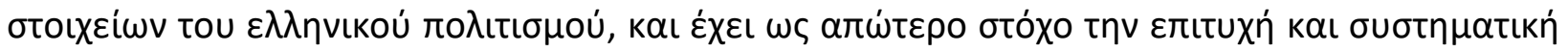

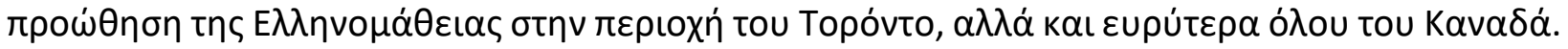

\section{References}

Byram, M. (2000). Assessing Intercultural Competence in Language Teaching. Sprogforum, 18(6), 8-13.

Byram, M., Gribkova, B., \& Starkey, H. (2002). Developingthe intercultural dimension in language teaching:A practical introduction for teachers. Strasbourg: Council of Europe.

Bourke, J. M. (1992). The case for problem-solving in second language learning. Occasional Paper 33. Dublin: Centre for Language and Communication Studies, Trinity College.

Council of Europe. (2001). Common European Framework of Reference for Languages. Learning, teaching, assessment. Cambridge University Press.

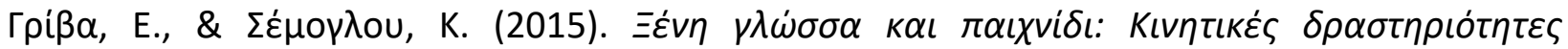

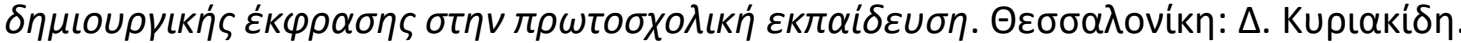

Harwood, N. (2010). English Language Teaching Materials: Theory and Practice. Cambridge: Cambridge University Press.

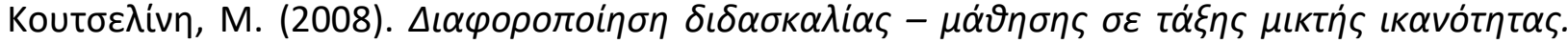
$\Lambda \varepsilon \cup \kappa \omega \sigma i \alpha$.

Norford, J., \& Marzano, R. (2016). Personalized Competency-Based Education: Creating a Cohesive and Coherent System. Marzano Research.

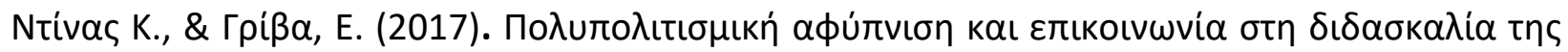

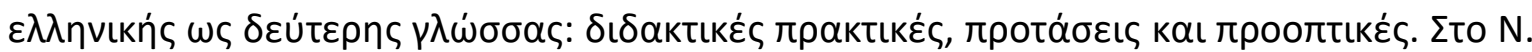




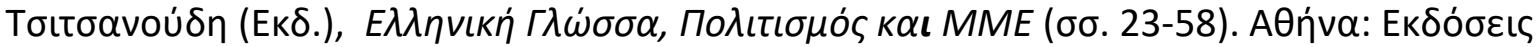
Gutenberg.

Nunan, D. (1998). Designing tasks for the communicative classroom. Cambridge: Cambridge University Press.

Ontario Curriculum. (2006). Language: grades 1-8. Ministry of Education. http://www.edu.gov.on.ca/eng/curriculum/elementary/language18currb.pdf

Richards, J. C., \& Renandya, W. A. (2002). Methodology in Language Teaching: An Anthology of Current Practice. New York: Cambridge University Press.

Rudvin, M., \& Spinzi, C. (2014). Negotiating the terminological borders of 'Language Mediation' in English and Italian. Languages - Cultures Mediation, 1-2, 57-79.

Sheen, R. (1992). Problem solving brought to task. RELC Journal 23/2, 44-61.

Tomlinson, C. A. (1999). The Differentiated Classroom. Responding to the Needs of All Learners. USA: ASCD.

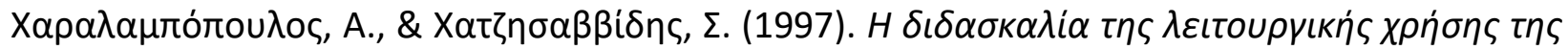

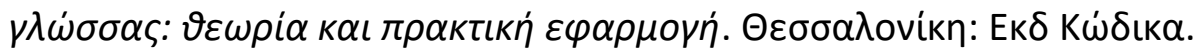

